\title{
Manilkara zapota (L.) P. Royen Leaf Water Extract Induces Apoptosis in Human Hepatocellular Carcinoma (HepG2) Cells via ERK1/2/Akt1/JNK1 Signaling Pathways
}

\author{
Bee Ling Tan $\mathbb{D}^{1},{ }^{1}$ Mohd Esa Norhaizan $\mathbb{D}^{1,2,3}$ and Lee Chin Chan $\mathbb{D}^{4}$ \\ ${ }^{1}$ Department of Nutrition and Dietetics, Faculty of Medicine and Health Sciences, Universiti Putra Malaysia, 43400 Serdang, \\ Selangor, Malaysia \\ ${ }^{2}$ Laboratory of Molecular Biomedicine, Institute of Bioscience, Universiti Putra Malaysia, 43400 Serdang, Selangor, Malaysia \\ ${ }^{3}$ Research Centre of Excellent, Nutrition and Non-Communicable Diseases (NNCD), Faculty of Medicine and Health Sciences, \\ Universiti Putra Malaysia, 43400 Serdang, Selangor, Malaysia \\ ${ }^{4}$ Department of Microbiology, Faculty of Biotechnology and Biomolecular Sciences, Universiti Putra Malaysia, 43400 Serdang, \\ Selangor, Malaysia
}

Correspondence should be addressed to Mohd Esa Norhaizan; nhaizan@upm.edu.my

Received 2 July 2018; Revised 5 October 2018; Accepted 22 October 2018; Published 5 November 2018

Academic Editor: Omer Kucuk

Copyright (C) 2018 Bee Ling Tan et al. This is an open access article distributed under the Creative Commons Attribution License, which permits unrestricted use, distribution, and reproduction in any medium, provided the original work is properly cited.

\begin{abstract}
Manilkara zapota (L.) P. Royen, called sapodilla, or locally known as ciku, belongs to the family Sapotaceae. We found that Manilkara zapota leaf water extract has cytotoxic effect against human hepatocellular carcinoma (HepG2) cell line in our earlier study. Therefore, this study aimed to explore the anticancer properties of Manilkara zapota leaf water extract in HepG2 cells. We also aimed to unravel yet undiscovered mechanisms and identified several expressed genes whose functions in cytotoxicity activity of Manilkara zapota leaf water extract in HepG2 cells have not been well-studied. The apoptosis and intracellular reactive oxygen species (ROS) activities were analyzed using Annexin V-propidium iodide staining and dichlorodihydrofluorescein diacetate, respectively, by NovoCyte Flow Cytometer. Bax and Bcl-2 expression were assessed using Enzyme-Linked Immunosorbent Assay. The associated molecular pathways were evaluated by quantitative real-time PCR. Overall analyses revealed that Manilkara zapota leaf water extract can increase percentage of early apoptotic cells, induce the formation of ROS, upregulate c-Jun N-terminal kinase 1 (JNK1) and inducible nitric oxide synthase (iNOS), and reduce Akt1 and vascular endothelial growth factor A (VEGFA) transcriptional activities. Our data suggest that Manilkara zapota leaf water extract can suppress the growth of HepG2 cells via modulation of ERK1/2/Akt1/JNK1 transcriptional expression.
\end{abstract}

\section{Introduction}

Liver cancer has become the second most common cause of death worldwide and contributes to approximately 746,000 deaths in 2012 [1]. It represents the ninth leading cancer in women $(228,000$ cases) and the fifth in men $(554,000$ cases) [1]. Although tremendous efforts have been made in the last few decades to improve the current therapeutic approaches, conventional therapy is not likely effective due to an adverse outcome, yet metastasis and recurrence still tend to occur. Most of the anticancer drugs demonstrated a narrow therapeutic window with limited selectivity against cancer cells [2]. The use of systemic chemotherapy is hindered due to the chemoresistant in HepG2 cells, either extrinsic or intrinsic $[3,4]$. Hence, the discovery of new anticancer agents from natural products has attracted an intense interest among scientists.

Mitogen-activated protein kinases (MAPKs), a family of threonine/serine protein kinases, are involved in the regulation of early apoptosis, which is crucial in several cellular processes, for example, cell adaptation and survival via phosphorylation of nuclear and cytoplasmic targets [5-8]. Inappropriate activation in MAPK signaling plays a crucial role in the progression and development of cancer [9]. Three 
distinct subgroups of MAPKs, namely, c-Jun N-terminal kinases (JNKs), protein kinase B (Akts), and extracellular signal-regulated kinases (ERKs), have been studied extensively [10]. Generally, JNKs are involved in the induction of apoptosis, while Akts and ERKs play a determining role in cell proliferation [11-13].

Inducible nitric oxide synthase (iNOS) has been associated with inflammation [14] by stimulating the expression of survival factors of cancer cells, thus suppressing the apoptosis. Apart from iNOS signaling, some of the well-known key angiogenesis and metastatic transcription factors described in in vivo study, including vascular endothelial growth factor A (VEGFA), have been demonstrated as potential therapeutic targets for cancer $[15,16]$. In line with this, a prompt action is urgently needed to develop apoptosis-inducing agents with high efficacy and specificity but showing minimal undesirable effects.

Manilkara zapota (L.) P. Royen, generally known as sapodilla, or locally called ciku (family: Sapotaceae), is an evergreen tree found abundantly throughout Indian subcontinent, for example, in Bangladesh [17], although it is native to Central America and Mexico. This plant is traditionally used as folk medicine for the treatment of diarrhea and ameliorates pulmonary infections [18]. Relative proportions of bioactive components in Manilkara zapota leaf such as lupeol acetate, oleanolic acid, myricetin-3-O- $\alpha$-L-rhamnoside, caffeic acid, and apigenin-7-O- $\alpha$-L-rhamnoside have been reported by Fayek et al. [19], which are known to exhibit potent antioxidant activities [20]. The previous finding has demonstrated that Manilkara zapota leaf ethyl acetate extract inhibits the Ehrlich ascites carcinoma in mice [21]. Nevertheless, there is no pharmacological study on anti-liver cancer properties of Manilkara zapota leaf water extract in the literature. We found that leaf water extract of Manilkara zapota exhibited cytotoxic activity against human hepatocellular carcinoma (HepG2) cell line (unpublished data). Therefore, Manilkara zapota leaf water extract has a great potential to be developed as complementary and alternative medicine for the treatment of liver cancer. Nonetheless, the underlying mechanisms of Manilkara zapota leaf water extract inducing cytotoxicity in HepG2 cells require further elucidation. In view of the ability of Manilkara zapota leaf water extract to induce cytotoxicity in HepG2 cells, the anticancer properties of leaf water extract of Manilkara zapota in HepG2 cells were undertaken. We aimed to unravel yet undiscovered mechanisms and identified several expressed genes whose functions in cytotoxicity activity of Manilkara zapota leaf water extract in HepG2 cells have not been well-studied. These multiple genes may be involved in the regulation of hepatocellular cancer and deserve further study and discussion.

\section{Materials and Methods}

2.1. Chemicals and Reagents. Mycoplex ${ }^{\mathrm{TM}}$ fetal bovine serum (FBS), trypsin EDTA (1×), penicillin and streptomycin $(100 \times)$, and RPMI-1640 medium were bought from Gibco (Grand Island, NY, USA). Annexin V-FITC Apoptosis Detection Kit I and Cycletest Plus DNA Reagent Kit were bought from BD Biosciences Pharmingen (Franklin Lakes, NJ, USA). Caspase Colorimetric assay kit was purchased from R\&D Systems (Minneapolis, MN, USA). Bax and Bcl-2 Human SimpleStep ELISA ${ }^{\circledR}$ Kits were procured from Abcam, UK.

2.2. Cell Culture. The human hepatocellular carcinoma (HepG2) cell line was procured from American Type Culture Collection (ATCC; Rockville, MD, USA). The HepG2 cells were grown in RPMI-1640 medium supplemented with $10 \%$ (v/v) FBS, $100 \mu \mathrm{g} / \mathrm{mL}$ streptomycin, and $100 \mathrm{IU} / \mathrm{mL}$ penicillin. The cells were grown at $5 \% \quad \mathrm{CO}_{2}$ atmosphere and $37^{\circ} \mathrm{C}$ humidified atmosphere incubator.

2.3. Plant Material. The plant (Manilkara zapota (L.) P. Royen) was collected from Pahang, Malaysia. The plant's authentication was conducted at Biodiversity Unit, Institute of Bioscience, Universiti Putra Malaysia (voucher specimen number: SK 3179/17).

2.4. Preparation of Plant Extract. Initially, leaf of Manilkara zapota was cut into small pieces and dried in an oven at $40^{\circ} \mathrm{C}$ for three days before being ground into powder form. Manilkara zapota leaf sample was extracted using water as previously reported by Tan et al. [22]. Five g of ground sample was extracted with $40 \mathrm{~mL}$ of water at $40^{\circ} \mathrm{C}$ for $2 \mathrm{~h}$. The slurry was filtered using filter paper (Whatman No. 1) and the residues were reextracted. Lastly, the filtrate from water extract was freeze-dried using a freeze drier (Tecan, Switzerland) to obtain a concentrated powder.

2.5. Cell Viability Assay. Cytotoxicity of Manilkara zapota leaf water extract on HepG2 cells was evaluated using 3(4,5-dimethylthiazol-2-yl)-2,5-diphenyltetrazolium bromide (MTT) assay [22]. Briefly, the HepG2 cells were seeded at a density of $5 \times 10^{4}$ cells/well in a 96-well plate. After $24 \mathrm{~h}$, the cells were treated with leaf water extract of Manilkara zapota. Untreated HepG2 cells (control) and 5-Fluorouracil (5-FU) (positive control) were also included. After treatment with Manilkara zapota leaf water extract for 24,48 , and $72 \mathrm{~h}$, $20 \mu \mathrm{L}(5 \mathrm{mg} / \mathrm{mL})$ of MTT was added to each well followed by incubation for 2-4 h. Active mitochondria in living cells reduced MTT to produce crystalline purple-blue formazan. After incubation for 2-4 h, media in each well were removed and $100 \mu \mathrm{L}$ of dimethyl sulfoxide (DMSO) was added to solubilize the purple-blue formazan. The absorbance was read at $570 \mathrm{~nm}$ using an ELISA microplate reader (Tecan, Switzerland), and $630 \mathrm{~nm}$ was used as a reference wavelength. Percentage of cell viability graph versus concentration of Manilkara zapota leaf water extract was plotted and the concentration of Manilkara zapota leaf water extract which inhibited $50 \%$ of cell viability compared to the control (50\% inhibitory concentration $\left(\mathrm{IC}_{50}\right)$ ) was assessed. The cell viability was measured as follows: 


$$
\begin{aligned}
& \text { Percentage of cell viability }(\%) \\
& =\frac{\mathrm{OD}_{570-630} \text { treatment }}{\mathrm{OD}_{570-630} \text { control }} \times 100
\end{aligned}
$$

where OD is the optical density.

2.6. Determination of Lactate Dehydrogenase Assay. Cytotoxicity was determined using an in vitro Toxicology Assay Kit by the release of lactate dehydrogenase (LDH), following the manufacturer's instruction. The cells were seeded at a density of $5 \times 10^{4}$ cells in each well of 96 -well plate. After an overnight incubation, the cells were exposed to different concentrations of Manilkara zapota leaf water extract for 24,48 , and $72 \mathrm{~h}$, and the supernatant was collected and used to determine the LDH activity. The LDH mixtures were added to each sample in a volume equal to twice the volume of medium removed. The reaction was halted after addition of $1 / 10(\mathrm{v} / \mathrm{v})$ of $1 \mathrm{~N} \mathrm{HCl}$ to each well and the absorbance was read at a wavelength of $490 \mathrm{~nm}$ using ELISA microplate reader (Tecan, Switzerland).

\subsection{Determination of Cell Morphological Changes of Apoptosis.} The HepG2 cells were seeded in each well of 6-well plate at a density of $1 \times 10^{5}$ cells per well in $2 \mathrm{~mL}$ of complete growth medium. After $24 \mathrm{~h}$ incubation, the cells were exposed to 24,48 , and $96 \mu \mathrm{g} / \mathrm{mL}$ of Manilkara zapota leaf water extract for 24,48 , and $72 \mathrm{~h}$. Untreated cells (control) were also included. The morphological changes and the characteristics of apoptosis of the untreated HepG2 cells and HepG2 cells treated with Manilkara zapota leaf water extract were viewed under an inverted light microscope (Olympus, Center Valley, PA, USA).

\subsection{Determination of Cell Cycle Arrest by Flow Cytometer.} The Cycletest Plus DNA Reagent Kit was used to assess cell cycle arrest, according to the manufacturer's instruction. The HepG2 cells were seeded in $25 \mathrm{~cm}^{2}$ tissue culture flask at a density of $1 \times 10^{5}$ cells and incubated for $24 \mathrm{~h}$. The cells were exposed to 24, 48, and $96 \mu \mathrm{g} / \mathrm{mL}$ Manilkara zapota leaf water extract for 24,48 , and $72 \mathrm{~h}$. HepG2 cells were then centrifuged at $30 \times g$ for $5 \mathrm{~min}$ at room temperature followed by the addition of a buffer solution. The cells were then added with $250 \mu \mathrm{L}$ of solution A (trypsin buffer) and $200 \mu \mathrm{L}$ of solution B (RNase buffer and trypsin inhibitor), followed by $10 \mathrm{~min}$ incubation at room temperature, respectively. The mixture was mixed with cold solution $\mathrm{C}(200 \mu \mathrm{L}$ of PI stain solution) and allowed to incubate for $10 \mathrm{~min}$ at $4^{\circ} \mathrm{C}$. Data acquisition and analysis were evaluated using NovoCyte Flow Cytometer (ACEA Biosciences, Inc.) with NovoExpress ${ }^{\circledR}$ software.

\subsection{Determination of Apoptosis by Annexin V-Propidium} Iodide Staining. The Annexin V-FITC Apoptosis Detection Kit I was used to analyze the activity of early and late apoptotic cells, according to the manufacturer's instruction. HepG2 cells were seeded in $25 \mathrm{~cm}^{2}$ tissue culture flask at a density of $1 \times 10^{6}$ cells followed by an overnight incubation. The cells were exposed to 24,48 , and $96 \mu \mathrm{g} / \mathrm{mL}$ of Manilkara zapota leaf water extract for 24,48 , and $72 \mathrm{~h}$. After incubation with the respective time interval, the cells were trypsinized and rinsed twice with phosphate-buffered saline-bovine serum albumin-ethylenediaminetetraacetic acid (PBS-BSA-EDTA) and the cell pellet was resuspended in $100 \mu \mathrm{L}$ of $1 \times$ binding buffer (0.1 M Hepes/NaOH, pH 7.4 and $1.4 \mathrm{M} \mathrm{NaCl}_{2}, 25$ $\mathrm{mM} \mathrm{CaCl} 2$ ). An aliquot of $5 \mu \mathrm{L}$ of Annexin $\mathrm{V}$-fluorescein isothiocyanate (FITC) and $10 \mu \mathrm{L}$ of propidium iodide (PI) were added to each sample and incubated for $10 \mathrm{~min}$ in the dark. Lastly, $400 \mu \mathrm{L}$ of $1 \times$ binding buffer was mixed with the cells and the fluorescence was evaluated using a NovoCyte Flow Cytometer (ACEA Biosciences, Inc.) with NovoExpress ${ }^{\circledR}$ software.

2.10. Determination of Bax and Bcl-2 Activities in Manilkara zapota Leaf Water Extract. The Bax and Bcl-2 activities were quantified using Bax and Bcl-2 Human SimpleStep ELISA ${ }^{\circledR}$ Kits, according to the manufacturer's protocol. Initially, HepG2 cells were seeded in $25 \mathrm{~cm}^{2}$ tissue culture flask at a density of $1 \times 10^{5}$ cells followed by an overnight incubation. The cells were treated with 24,48, and $96 \mu \mathrm{g} / \mathrm{mL}$ of Manilkara zapota leaf water extract for $72 \mathrm{~h}$. The cells were trypsinized and centrifuged at $500 \times g$ for $5 \mathrm{~min}$ at $4^{\circ} \mathrm{C}$ to remove the medium. The cells were rinsed twice with phosphatebuffered saline (PBS) and cold $1 \times$ Cell Extraction Buffer PTR, followed by incubation on ice for $20 \mathrm{~min}$. The cell lysates were subsequently centrifuged at $18,000 \times g$ and $4^{\circ} \mathrm{C}$ for $20 \mathrm{~min}$, and the supernatants were collected. The protein concentrations were quantified using Bradford protein assay kit. An aliquot of the sample was diluted to the desired concentration in $1 \times$ Cell Extraction Buffer PTR. About $50 \mu \mathrm{L}$ of standard or sample was then added to $50 \mu \mathrm{L}$ of antibody cocktail in each well of 96-well plate. The plate was sealed prior to incubation for $1 \mathrm{~h}$ at room temperature on a plate shaker set to $400 \times g$. Each well was rinsed with $3 \times 350 \mu \mathrm{L}$ $1 \times$ wash buffer PT. An aliquot of $100 \mu \mathrm{L}$ of TMB substrate was added to each well followed by $10 \mathrm{~min}$ incubation in the dark on a plate shaker set to $400 \times g$. Subsequently, 100 $\mu \mathrm{L}$ of Stop Solution was added to each well and read at the wavelength of $450 \mathrm{~nm}$. Human Bax or Bcl-2 protein was used as a standard. The Bax standard stock solution (400 $\mathrm{ng} / \mathrm{mL}$ ) was prepared by adding $200 \mu \mathrm{L}$ of deionized water, followed by $10 \mathrm{~min}$ incubation. An aliquot of $225 \mu \mathrm{L}$ of $1 \times$ Cell Extraction Buffer PTR was added to tube number 1 and $150 \mu \mathrm{L}$ of $1 \times$ Cell Extraction Buffer PTR was added to tubes numbers 2-8. The stock solution was prepared using the dilution series. Standard tube number 8 contains no protein (blank control). The human Bcl-2 standard stock solution $(200 \mathrm{ng} / \mathrm{mL})$ was prepared by adding $1 \mathrm{~mL}$ of $1 \times$ Cell Extraction PTR incubated at room temperature for $3 \mathrm{~min}$. Standards 2-8 were added with $150 \mu \mathrm{L}$ of $1 \times$ Cell Extraction Buffer PTR into each tube. A working dilution of $\mathrm{Bcl}-2$ standard was prepared using a dilution series. Standard tube number 8 contains no protein (blank control).

2.11. Caspase-3 and Caspase- 8 Assay. The caspase-3 and 8 activities were evaluated spectrophotometrically using a commercial colorimetric assay kit. Briefly, HepG2 cells were seeded in 6-well plate at a density of $1 \times 10^{5}$ cells. After an 
overnight incubation, the cells were exposed to 24,48 , and $96 \mu \mathrm{g} / \mathrm{mL}$ of Manilkara zapota leaf water extract for $72 \mathrm{~h}$. The cells were trypsinized and centrifuged at $250 \times g$ for 10 min to discard the medium. The cell pellets were then lysed in $25 \mu \mathrm{L}$ of cold lysis buffer, followed by $10 \mathrm{~min}$ incubation on ice. The cell lysates were subsequently centrifuged at 10,000 $\times g$ and $4^{\circ} \mathrm{C}$ for $1 \mathrm{~min}$, and the supernatants were collected. The protein concentrations were quantified using Bradford protein assay kit. An aliquot of $50 \mu \mathrm{L}$ of $2 \times$ Reaction Buffer 3 or $2 \times$ Reaction Buffer 8 was mixed with $50 \mu \mathrm{L}$ of cell lysate containing $200 \mu \mathrm{g}$ of total protein, followed by $5 \mu \mathrm{L}$ of caspase- 3 or caspase- 8 colorimetric substrate (DEVD- $p \mathrm{Na}$ or IETD- $p \mathrm{Na}$ ). Lastly, the reaction mixture was incubated at $37^{\circ} \mathrm{C}$ for $2 \mathrm{~h}$ before being read at a wavelength of $405 \mathrm{~nm}$ using ELISA microplate reader (Tecan, Switzerland).

2.12. Determination of Intracellular Reactive Oxygen Species in Manilkara zapota Leaf Water Extract. Dichlorodihydrofluorescein diacetate (DCFH-DA) was used to evaluate intracellular reactive oxygen species (ROS) in HepG2 cells treated with Manilkara zapota leaf water extract. Briefly, HepG2 cells were seeded in 6-well plate at a density of $1 \times 10^{5}$ cells/well in $2 \mathrm{~mL}$ of complete media for overnight and pretreated with $10 \mu \mathrm{M}$ DCFH-DA in complete media for $1 \mathrm{~h}$. The excess DCFH-DA was discarded and rinsed twice with PBS, followed by treatment with Manilkara zapota leaf water extract for $3 \mathrm{~h}$. Following incubation, both adherent and floating cells were collected. The samples were then measured using NovoCyte Flow Cytometer (ACEA Biosciences, Inc.) with NovoExpress ${ }^{\circledR}$ software.

2.13. Determination of Antioxidants on Manilkara zapota Leaf Water Extract Induced Cell Death in HepG2 Cells. Briefly, the HepG2 cells were seeded at a density of $5 \times 10^{4}$ cells/well in a 96-well plate, followed by an overnight incubation. The cells were treated with leaf water extract of Manilkara zapota or cotreated with $50 \mu \mathrm{M} \alpha$-tocopherol or ascorbic acid for $72 \mathrm{~h}$. An aliquot of $20 \mu \mathrm{L}$ MTT $(5 \mathrm{mg} / \mathrm{mL})$ was added to each well followed by incubation for $2-4 \mathrm{~h}$. The media in each well were removed and $100 \mu \mathrm{L}$ of DMSO was added to solubilize the purple-blue formazan. The absorbance was read at $570 \mathrm{~nm}$ using an ELISA microplate reader (Tecan, Switzerland), and $630 \mathrm{~nm}$ was used as a reference wavelength. The percentage of cell viability graph versus concentration of Manilkara zapota leaf water extract was plotted. The cell viability was measured as follows:

$$
\begin{aligned}
& \text { Percentage of cell viability }(\%) \\
& =\frac{\mathrm{OD}_{570-630} \text { treatment }}{\mathrm{OD}_{570-630} \text { control }} \times 100
\end{aligned}
$$

where OD is the optical density.

2.14. Total RNA Extraction and Quantification. Total ribonucleic acid (RNA) was isolated using TRI Reagent ${ }^{\circledR}$, according to the manufacturer's instruction. The HepG2 cells were seeded at a density of $1 \times 10^{5}$ cells in a $25 \mathrm{~cm}^{2}$ culture flask for $24 \mathrm{~h}$. After incubation for $72 \mathrm{~h}$ at different concentrations
$(24,48$, and $96 \mu \mathrm{g} / \mathrm{mL})$ of Manilkara zapota leaf water extract, the cells were homogenized and the lysates were aliquoted in microcentrifuge tubes. An aliquot of $1 \mathrm{~mL}$ TRI Reagent ${ }^{\circledR}$ was added in $25 \mathrm{~cm}^{2}$ tissue culture flask and resuspended. The homogenized sample was incubated for $5 \mathrm{~min}$ at room temperature to allow the dissociation of nuclear protein complexes. Hundred $\mu \mathrm{L}$ of 1-bromo-3-chloropropane per $\mathrm{mL}$ of TRI Reagent ${ }^{\circledR}$ used was mixed and vortexed vigorously for $15 \mathrm{~s}$ followed by 2-15 min incubation at room temperature. After centrifugation for $15,000 \times g$ and $2-8^{\circ} \mathrm{C}$ for $15 \mathrm{~min}$, the mixture was divided into a lower red organic layer, an interphase, and a colorless upper aqueous layer containing RNA. The aqueous layer was precipitated after the addition of $500 \mu \mathrm{L}$ of isopropanol. The sample was incubated for 5-10 min at room temperature prior to centrifugation at $11,500 \times g$ and $2-8^{\circ} \mathrm{C}$ for $10 \mathrm{~min}$. The supernatant was discarded and the RNA pellet was washed with $1 \mathrm{~mL}$ of $75 \%$ (v/v) ethanol before being centrifuged at $5,500 \times g$ and $2-8^{\circ} \mathrm{C}$ for $5 \mathrm{~min}$. Fifty $\mu \mathrm{L}$ of RNase free water was mixed with the RNA pellet and resuspended before being stored at $-80^{\circ} \mathrm{C}$. The RNA concentration was read at $260 \mathrm{~nm}$ using a nanophotometer.

2.15. cDNA Synthesis. RNA sample was reverse-transcribed using the iScript ${ }^{\mathrm{TM}}$ gDNA Clear cDNA Synthesis Kit, according to the manufacturer's protocol. Briefly, $0.5 \mu \mathrm{L}$ of iScript DNase was added to $1.5 \mu \mathrm{L}$ of iScript DNase Buffer to make a DNase master mix. Two microliters of the DNase master mix was mixed with $14 \mu \mathrm{L}$ of RNA with an RNA amount of 2 $\mu \mathrm{g}$. The DNase reaction was conducted using a thermal cycler with the following mode and held at $4^{\circ} \mathrm{C}$ : $25^{\circ} \mathrm{C}$ for $5 \mathrm{~min} ; 75^{\circ} \mathrm{C}$ for $5 \mathrm{~min}$. The cDNA synthesis reaction mix was performed by adding $4 \mu \mathrm{L}$ of iScript Reverse Transcription Supermix and $16 \mu \mathrm{L}$ of DNase-treated RNA templates. The reverse transcription reaction was performed using an Authorized Thermal Cycler (Eppendorf, NY, USA) with the following conditions and held at $4^{\circ} \mathrm{C}$ : $25^{\circ} \mathrm{C}$ for $5 \mathrm{~min} ; 46^{\circ} \mathrm{C}$ for $20 \mathrm{~min}$; $95^{\circ} \mathrm{C}$ for $1 \mathrm{~min}$.

2.16. Optimization of Primer Annealing Temperature. In order to optimize the annealing temperature of the designed primer sets, $2 \mu \mathrm{L}$ of cDNA $(20 \mathrm{ng} / \mu \mathrm{L})$ was amplified using realtime polymerase chain reaction (PCR). Based on optimum annealing temperatures suggested by the manufacturer for the different primer sets, a gradient PCR program was conducted at different annealing temperatures ranging from $50.0^{\circ} \mathrm{C}$ to $63.0^{\circ} \mathrm{C}$ with 8 intervals $\left(50.0^{\circ} \mathrm{C}, 50.8^{\circ} \mathrm{C}, 52.6^{\circ} \mathrm{C}\right.$, $55.1^{\circ} \mathrm{C}, 58.2^{\circ} \mathrm{C}, 60.8^{\circ} \mathrm{C}, 62.3^{\circ} \mathrm{C}$, and $63.0^{\circ} \mathrm{C}$ ) in $\mathrm{CFX}^{\mathrm{TM}}$ RealTime System (Bio-Rad, Hercules, CA, USA).

2.17. Determination of Real-Time PCR Detection Limit and Primer Efficiency. To evaluate the detection limit and binding effect of the developed real-time PCR assay, a series of 10-fold dilution from undiluted sample to $10^{-4}$ of cDNA was prepared as a positive control while nuclease-free water was served as a non-template negative control. The detection limit of the assay was determined by analyzing the correlation between the concentration of the DNA template and Cq values as a standard curve. 
TABLE 1: Nucleotide sequence of PCR primers for amplification and sequence-specific detection of cDNA (obtained from the GenBank database).

\begin{tabular}{|c|c|}
\hline $\begin{array}{l}\text { Primer name } \\
\text { [accession number] }\end{array}$ & Oligonucleotides $\left(5^{\prime}-3^{\prime}\right)$ sequence \\
\hline ERK1/2 [NM_002745.4] & $\begin{array}{l}\text { F- CCACCCATATCTGGAGCAGT } \\
\text { R- CAGTCCTCTGAGCCCTTGTC }\end{array}$ \\
\hline$A k t 1[A B 451242]$ & $\begin{array}{l}\text { F- AGAAGCAGGAGGAGGAGGAG } \\
\text { R- TCTCCTTCACCAGGATCACC }\end{array}$ \\
\hline JNK1 [NM_139046.3] & $\begin{array}{l}\text { F- GTGATCAATGGCTCTCAGCA } \\
\text { R- TGACTAACCGACTCCCCATC }\end{array}$ \\
\hline iNOS [AF049656.1] & $\begin{array}{l}\text { F- GTGGTGACAAGCACATTTGG } \\
\text { R- GTCATGAGCAAAGGCACAGA }\end{array}$ \\
\hline VEGFA [NM_001287044.1] & $\begin{array}{l}\text { F- CCCACTGAGGAGTCCAACAT } \\
\text { R- AAATGCTTTCTCCGCTCTGA }\end{array}$ \\
\hline$A C T B^{\mathrm{a}}$ [NM_001101.3] & $\begin{array}{l}\text { F- AGAGCTACGAGCTGCCTGAC } \\
\text { R- AGCACTGTGTTGGCGTACAG }\end{array}$ \\
\hline$G A P D H^{\mathrm{a}}$ [NM_002046.4] & $\begin{array}{l}\text { F- GGATTTGGTCGTATTGGGC } \\
\text { R- TGGAAGATGGTGATGGGATT }\end{array}$ \\
\hline $18 \mathrm{~S} \mathrm{rRNA}^{\mathrm{a}}[\mathrm{HQ} 387008.1]$ & $\begin{array}{l}\text { F- GTAACCCGTTGAACCCCATT } \\
\text { R- CCATCCAATCGGTAGTAGCG }\end{array}$ \\
\hline
\end{tabular}

ACTB: beta-actin; ERK1/2: extracellular signal-regulated kinase 1/2; GAPDH: glyceraldehyde-3-phosphate dehydrogenase; iNOS: inducible nitric oxide synthase; JNK1: c-Jun N-terminal kinase 1; VEGFA: vascular endothelial growth factor A.

${ }^{\mathrm{a}}$ Housekeeping gene

2.18. Quantitative Real-Time Polymerase Chain Reaction ( $q R T-P C R)$. Real-time PCR assay was performed using the designed primer sets with optimum annealing temperature determined from annealing temperature gradient analysis. Briefly, approximately $2 \mu \mathrm{L}$ of cDNA $(20 \mathrm{ng} / \mu \mathrm{L})$ from Manilkara zapota leaf water extract was amplified using realtime PCR reaction using the designed primer sets originating from human cell lines (Table 1). PCR assay was conducted with the following conditions: $95.0^{\circ} \mathrm{C}$ for $2 \mathrm{~min}$, followed by 39 cycles of $95^{\circ} \mathrm{C}$ for $5 \mathrm{sec}, 55^{\circ} \mathrm{C}$ for $10 \mathrm{sec}$, and $72^{\circ} \mathrm{C}$ for $20 \mathrm{sec}$, before the fluorescence reading was recorded. The reactions were then incubated from $55.0^{\circ} \mathrm{C}$ to $95.0^{\circ} \mathrm{C}$ with $0.5^{\circ} \mathrm{C}$ increment per $10 \mathrm{sec}$ for melt curve analysis. The fluorescence threshold limit of the $\mathrm{CFX}^{\mathrm{TM}}$ Real-Time System (Bio-Rad, Hercules, CA, USA) was set at 100 relative fluorescence units (RFU).

2.19. Statistical Analyses. Data are shown as means \pm standard deviation with 3 independent analyses. The statistical significance of the difference between the control and treatment groups was analyzed using a one-way analysis of variance (ANOVA). Statistical analyses were performed using the Statistical Package for Social Science (SPSS) version 19.0 (SPSS Inc., Chicago, IL, USA). A $P$ value less than 0.05 was considered statistically significant.

\section{Results and Discussion}

3.1. Manilkara zapota Leaf Water Extract Was Cytotoxic and Inhibits the Proliferation of HepG2 Cells. Extensive histological and molecular evidence supporting the association between the apoptosis and anticancer activity of pharmaceutical agents has attracted many researchers to investigate new anticancer agents with potential apoptotic-inducing effect $[23,24]$. Towards understanding the cells viability of Manilkara zapota leaf water extract on HepG2 cells, the apoptosis-inducing activity of Manilkara zapota leaf water extract was evaluated in HepG2 cells. According to published guidelines, any extract exerts potentially cytotoxic activities should have an $\mathrm{IC}_{50}$ less than $100 \mu \mathrm{g} / \mathrm{mL}$ [25]. As presented in Figure 1(a), treatment with Manilkara zapota leaf water extract at higher concentrations $(12.5-200 \mu \mathrm{g} / \mathrm{mL})$ for 24 $h$ resulted in a significant reduction in the cell viability compared to the untreated cells (control) $(P<0.05)$. Consistent with the effects observed in $24 \mathrm{~h}$, HepG2 cells also significantly reduced the cells viability after treatment with Manilkara zapota leaf water extract at 48 and $72 \mathrm{~h}$ compared to the control $(P<0.05)$, with the concentrations ranging from 3.13 to $200 \mu \mathrm{g} / \mathrm{mL}$. Prolong incubation time period up to $72 \mathrm{~h}$ caused the HepG2 cells to become more sensitive compared to $24 \mathrm{~h}$ (Figure $1(\mathrm{a})$ ), with the $\mathrm{IC}_{50}$ value of 112.69 $\pm 6.51,178.76 \pm 8.57$, and $48.24 \pm 3.47 \mu \mathrm{g} / \mathrm{mL}$, respectively (unpublished data).

To address whether Manilkara zapota leaf water extract affected the proliferation of liver cancer cells, we treated HepG2 cells with different concentrations of Manilkara zapota leaf water extract and analyzed them using 3(4,5-dimethylthiazol-2-yl)-2,5-diphenyltetrazolium bromide (MTT) and lactate dehydrogenase (LDH) leakage assays. In $\mathrm{LDH}$ assay, after irreversible cells membrane damage, a stable cytosolic enzyme of $\mathrm{LDH}$ that catalyzes the oxidation

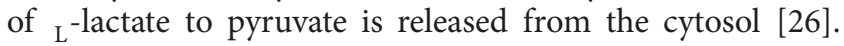
As shown in Figure 1(b), incubation Manilkara zapota leaf water extract for $24 \mathrm{~h}$ reduced the proliferation of HepG2 cells in a dose-dependent manner. A similar trend was also noted at 48 and $72 \mathrm{~h}$. The $\mathrm{IC}_{50}$ values of Manilkara zapota 


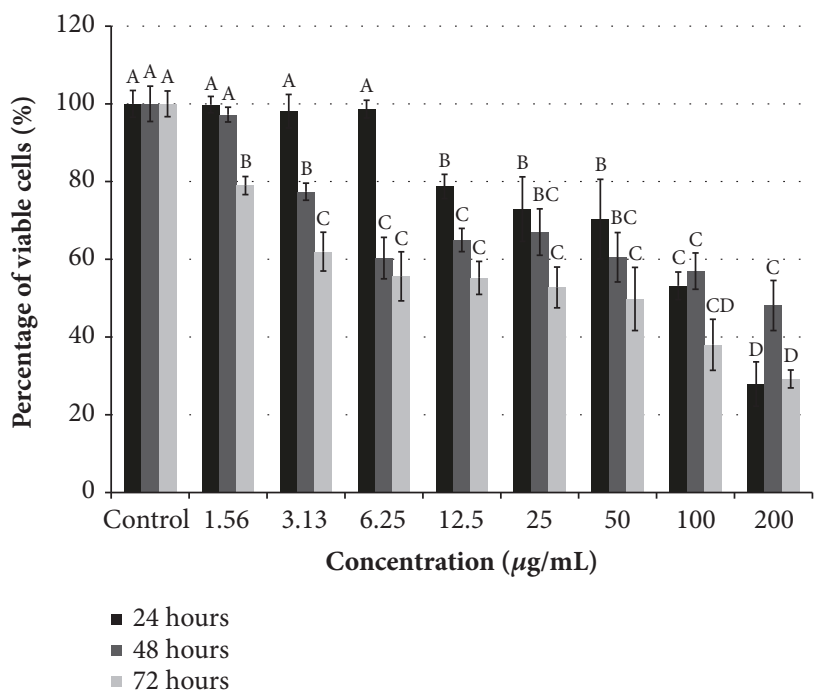

(a)

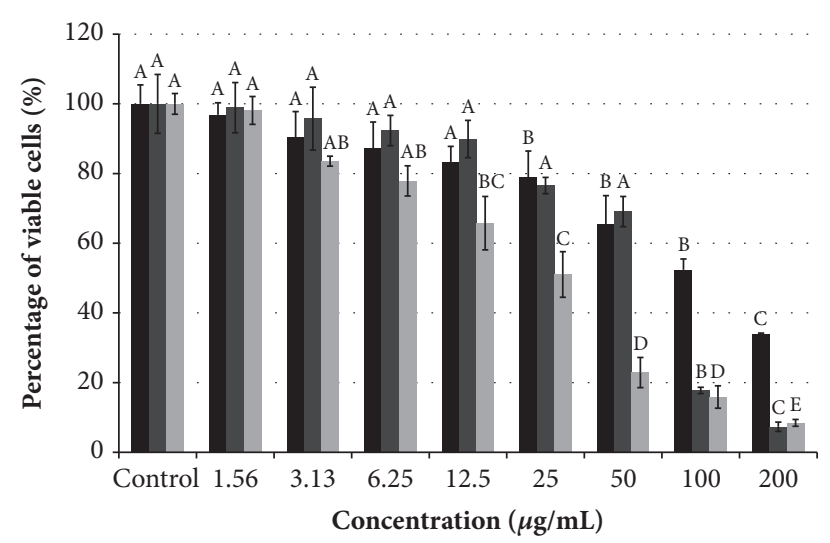

- 24 hours
- 48 hours
- 72 hours

(b)

FIGURE 1: Cytotoxicity effect of Manilkara zapota leaf water extract on HepG2 cells. Cytotoxic effect of Manilkara zapota leaf water extract was evaluated on (a) MTT and (b) LDH assays. Values are reported as mean \pm SD $(n=3)$. Value with different superscript letter indicates significant difference between groups by Tukey's test $(P<0.05)$. The percentage of viable cells was significantly inhibited at $24 \mathrm{~h}$ after treatment at higher concentrations $(25-200 \mu \mathrm{g} / \mathrm{mL})$ compared to the untreated cells (control) in both MTT and LDH assays $(P<0.05)$. Treatment with $100-200 \mu \mathrm{g} / \mathrm{mL}$ of Manilkara zapota leaf water extract for 48 and $72 \mathrm{~h}$ significantly reduced the cells viability in both MTT and LDH assays $(P<0.05)$. MTT: 3-(4,5-dimethylthiazol-2-yl)-2,5-diphenyltetrazolium bromide; LDH: lactate dehydrogenase.

leaf water extract towards HepG2 cells at 24, 48, and $72 \mathrm{~h}$ were $102.85 \pm 7.96,68.59 \pm 9.14$, and $49.07 \pm 6.35 \mu \mathrm{g} / \mathrm{mL}$, respectively (unpublished data). Our $\mathrm{LDH}$ finding proved that Manilkara zapota leaf water extract was cytotoxic to HepG2, similar to the data shown from MTT proliferation assay, even though the findings of MTT assay exhibited a stronger cytotoxic effect on HepG2 cells. Based on the cytotoxic effect as evaluated by MTT and LDH assays, three concentrations $(24,48$, and $96 \mu \mathrm{g} / \mathrm{mL})$ were selected for further analyses.

As a positive control, the HepG 2 cells were incubated with the commercial drug, 5-Fluorouracil (5-FU). The $\mathrm{IC}_{50}$ values of 5-FU against HepG2 cells at 24, 48, and $72 \mathrm{~h}$ were 10.35 $\pm 4.79,7.94 \pm 2.91$, and $2.55 \pm 0.92 \mu \mathrm{g} / \mathrm{mL}$, respectively, as evaluated using MTT assay. Consistent with the MTT results, the findings from $\mathrm{LDH}$ assay also demonstrated that 5-FU suppresses the viability of HepG 2 cells in a time-dependent manner, with $\mathrm{IC}_{50}$ values of $11.29 \pm 4.94,8.96 \pm 3.52$, and 3.08 $\pm 0.94 \mu \mathrm{g} / \mathrm{mL}$ at 24,48 , and $72 \mathrm{~h}$, respectively.

3.2. Morphological Changes of HepG2 Cells following Treatment with Manilkara zapota Leaf Water Extract. The morphological study revealed that Manilkara zapota leaf water extract induced growth inhibition and apoptosis in HepG2 cells. A marked inhibitory effect was also noted in HepG2 cells treated with $2.8 \mu \mathrm{g} / \mathrm{mL}$ of 5-FU. As depicted in Figure 2, the number of cells in the group treated with $24 \mu \mathrm{g} / \mathrm{mL}$ of Manilkara zapota leaf water extract was decreased compared to control from $24 \mathrm{~h}$ to $72 \mathrm{~h}$. The growth of cells was inhibited after $48 \mathrm{~h}$ of incubation with 48 and $96 \mu \mathrm{g} / \mathrm{mL}$ of Manilkara zapota leaf water extract and this phenomenon became more obvious at $72 \mathrm{~h}$ (Figure 2). Cell detachment was noted in HepG2 cells treated with $24 \mu \mathrm{g} / \mathrm{mL}$ and in the latter (48 and $96 \mu \mathrm{g} / \mathrm{mL}$ ) from $24 \mathrm{~h}$ to $72 \mathrm{~h}$. Notably, cell rounding and detachment of HepG2 cells were accompanied by an altered chromatin structure with a typical apoptotic morphology such as cellular shrinkage (CS), apoptotic bodies $(\mathrm{AB})$, nuclear fragmentation (NF), and membrane blebbing (MB) (Figure 3).

\subsection{Treatment with Manilkara zapota Leaf Water Extract} Induces Cell Cycle Arrest in HepG2 Cells. Deregulation of the cell division process caused an uncontrolled proliferation and resulted in the development of tumor [27]. The ability to arrest cell cycle progression may serve as a potential anticancer agent [28]. To verify whether Manilkara zapota leaf water extract induced growth inhibition in HepG2 cells is modulated by cellular apoptosis and cell cycle arrest, the cells were incubated with different concentrations of Manilkara zapota leaf water extract for 24,48 , and $72 \mathrm{~h}$ and measured by flow cytometry (Figure 4(a)). Our analysis showed that a significant increase in the percentage of cells at $\mathrm{G}_{2} / \mathrm{M}$ phase was noted at 24, 48, and $96 \mu \mathrm{g} / \mathrm{mL}$ of Manilkara zapota leaf water extract $(P<0.05)$ (Figure $4(\mathrm{~b}))$. This finding indicates that Manilkara zapota leaf water extract elicited arrest at $\mathrm{G}_{2} / \mathrm{M}$ phase following $24 \mathrm{~h}$ of treatment at all tested concentrations $(24,48$, and $96 \mu \mathrm{g} / \mathrm{mL})$.

As illustrated in Figure 4(c), treatment with Manilkara zapota leaf water extract at 24, 48, and $96 \mu \mathrm{g} / \mathrm{mL}$ for 48 $h$ significantly increased the population of cells at $G_{2} / M$ phase compared to the control $(P<0.05)$. In the present study, the treatment of Manilkara zapota leaf water extract 

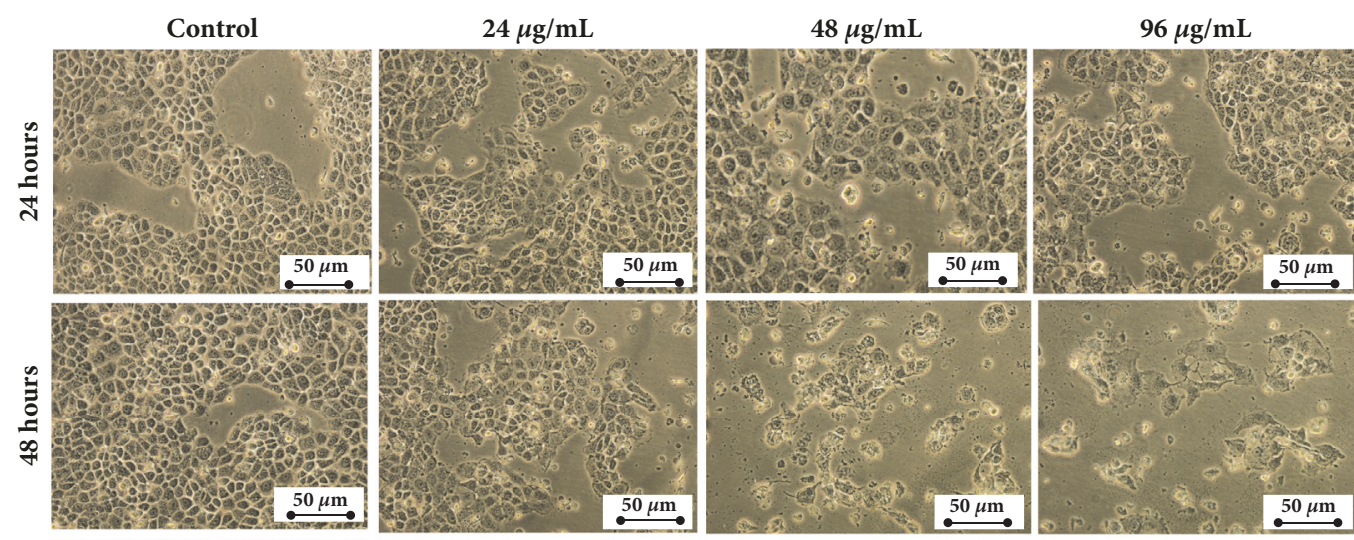

5-FU $2.8 \mu \mathrm{g} / \mathrm{mL}$
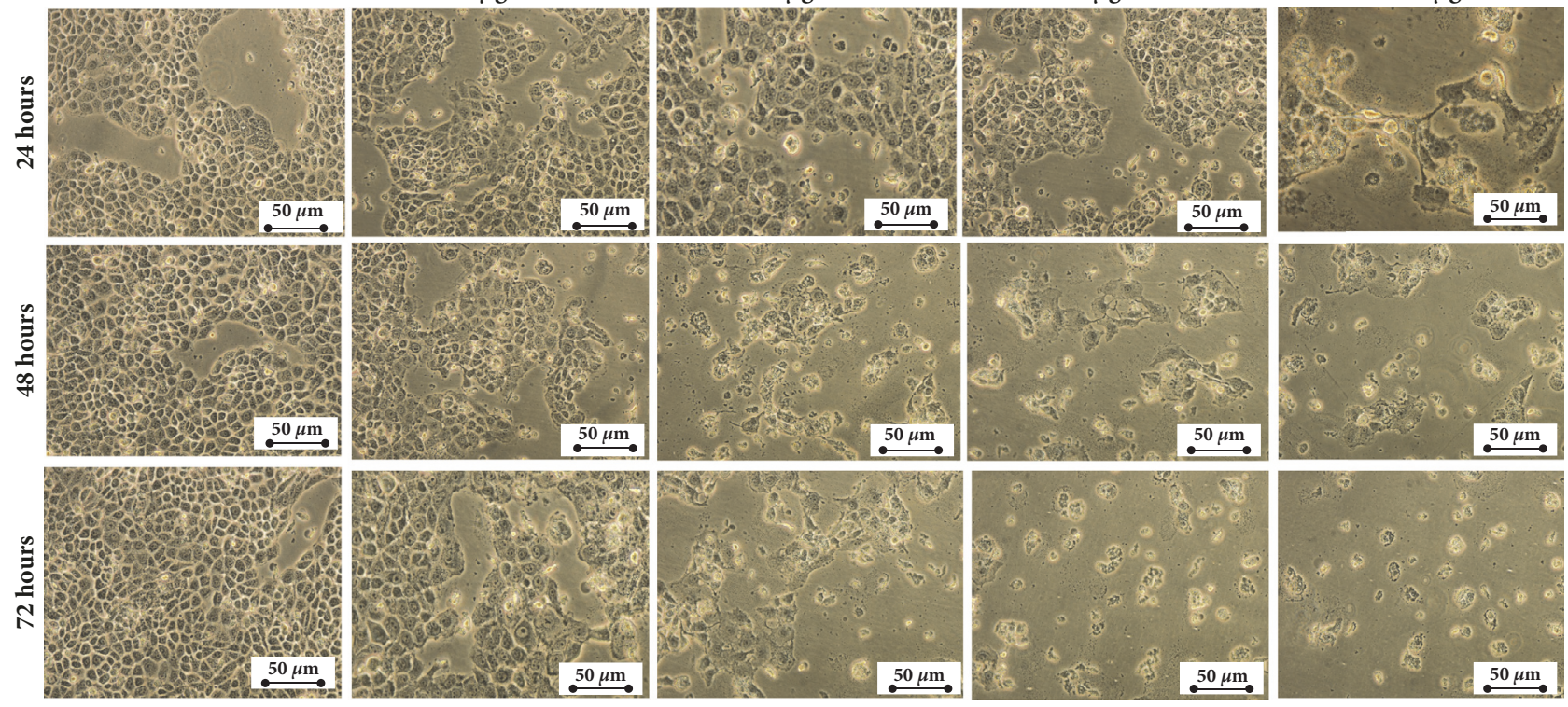

Figure 2: Morphological changes of HepG2 cells after treatment with Manilkara zapota leaf water extract (magnification $200 \times$ ). Manilkara zapota leaf water extract inhibits the proliferation of HepG2 cells.
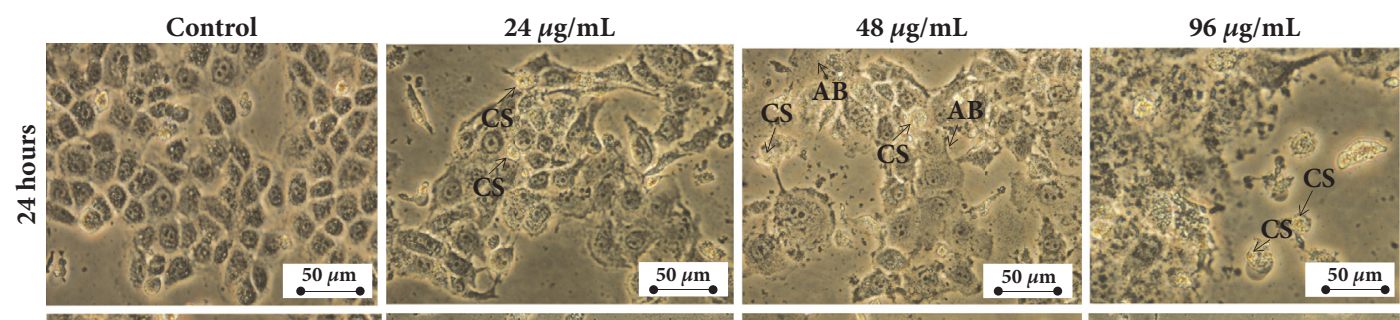

\section{$5-\mathrm{FU} 2.8 \mu \mathrm{g} / \mathrm{mL}$}
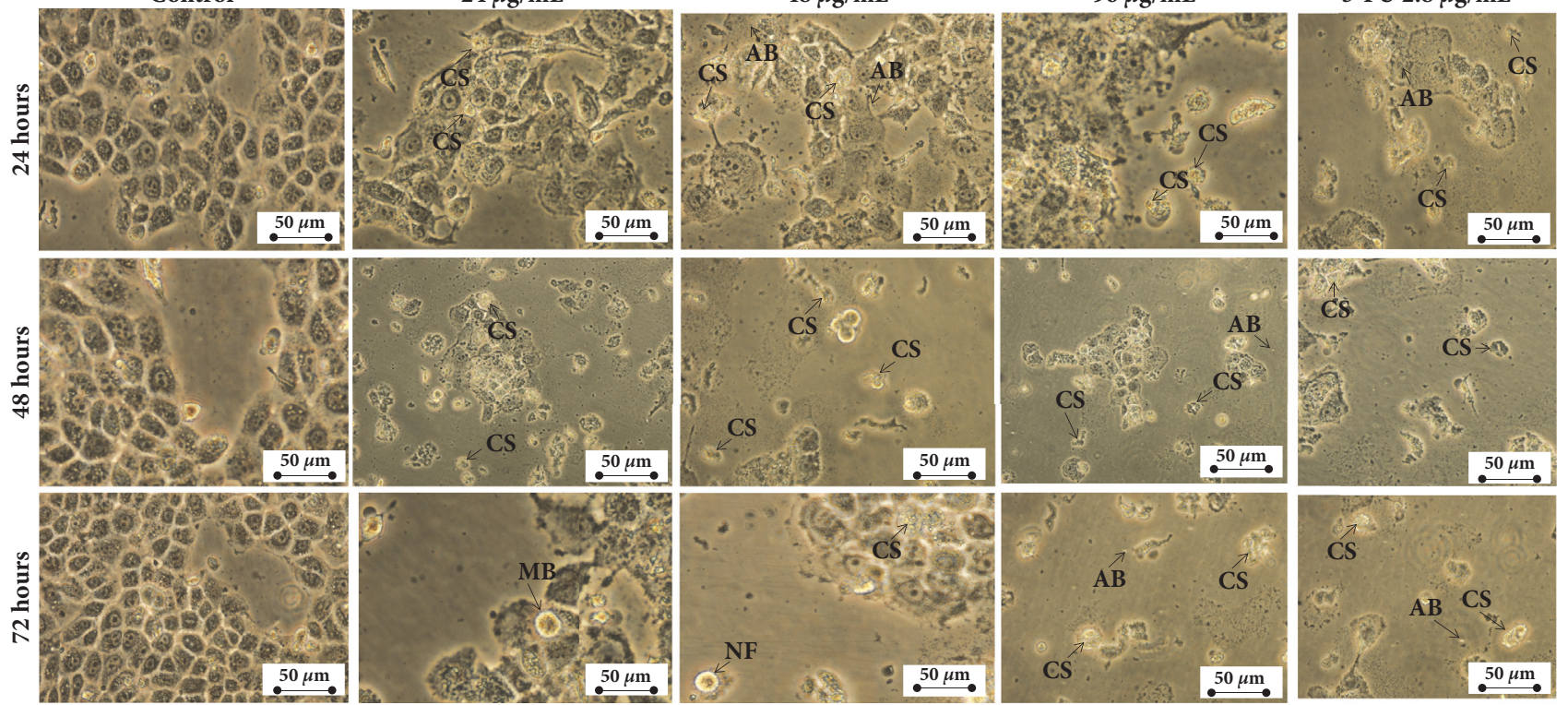

FIGURE 3: Close-up view of morphological changes in HepG2 cells after treatment with Manilkara zapota leaf water extract (magnification $400 \times$ ) viewed under an inverted light microscope. The cells showed the apoptosis characteristics such as cellular shrinkage (CS), apoptotic bodies $(\mathrm{AB})$, nuclear fragmentation $(\mathrm{NF})$, and membrane blebbing $(\mathrm{MB})$ (magnification $400 \times$ ).

elicited non-phase specific cell cycle arrest in HepG2 cells. On the other hand, treatment with Manilkara zapota leaf water extract at 48 and $96 \mu \mathrm{g} / \mathrm{mL}$ significantly increased the population of cells at $\mathrm{G}_{0} / \mathrm{G}_{1}$ phase as compared to the control $(P<0.05)$ with a concomitant decrease of the $\mathrm{S}$ phase at $72 \mathrm{~h}$ (Figure $4(\mathrm{~d})$ ). The data we presented in this study demonstrated that Manilkara zapota leaf water extract destroys tumor cells in either dividing or resting state. The non-specific phase drug is considered as the most effective drug combating slow-growing tumors [29]. The mode of a non-phase specific antitumor agent is highly dependent on the incubation time and concentration [30]. This is also true for Manilkara zapota leaf water extract, whereby the growth inhibitory activity was observed in this study. Collectively, the data presented in this study suggest that the concentration and incubation time of Manilkara zapota leaf water extract may influence the effects on cell cycle. 


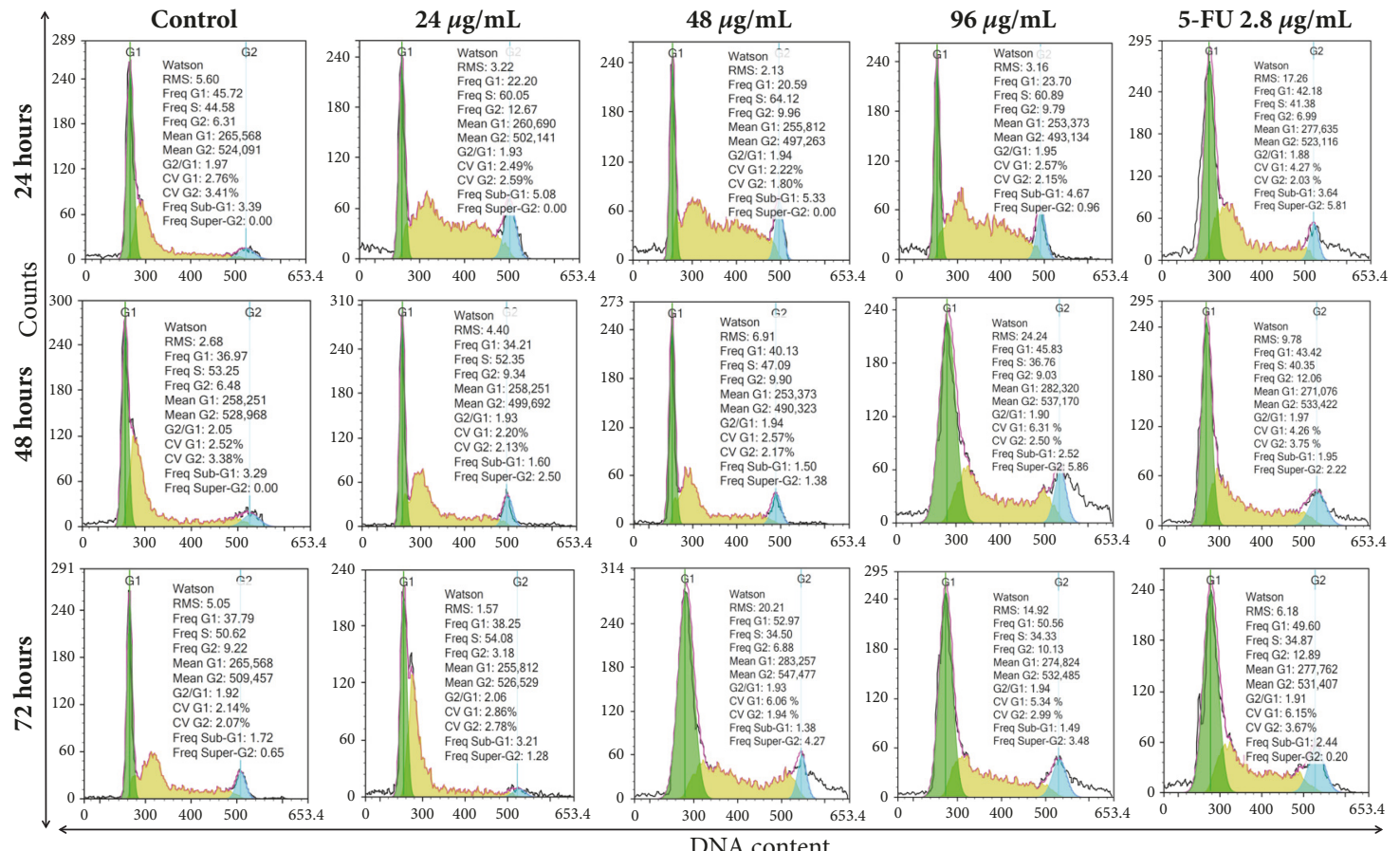

(a)

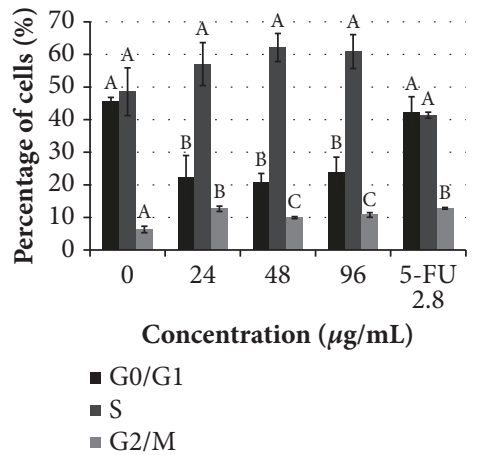

(b)

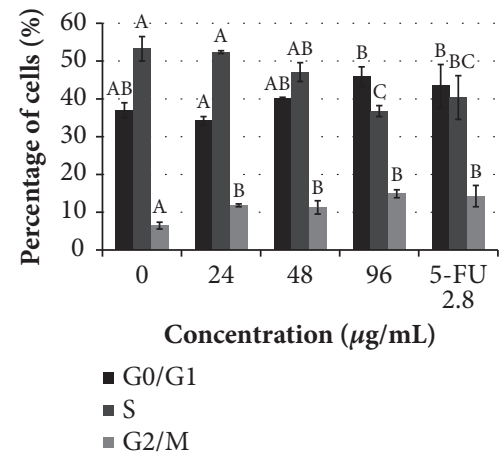

(c)

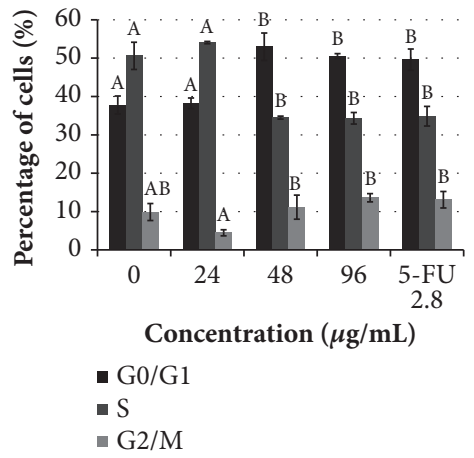

(d)

FIGURE 4: Cell cycle phase distribution of (a) untreated HepG2 cells and Manilkara zapota leaf water extract and 5-Fluorouracil (5-FU) treated HepG2 cells for (b) $24 \mathrm{~h}$, (c) $48 \mathrm{~h}$, and (d) $72 \mathrm{~h}$, analyzed using flow cytometry. Values are reported as mean \pm SD ( $=3$ ). Value with different superscript letter indicates significant difference between groups by Tukey's test $(P<0.05)$. (b) A significant increase in the percentage of cells at $\mathrm{G}_{2} / \mathrm{M}$ phase was noted at 24,48 , and $96 \mu \mathrm{g} / \mathrm{mL}$ of Manilkara zapota leaf water extract after $24 \mathrm{~h}(P<0.05)$. (c) Treatment with Manilkara

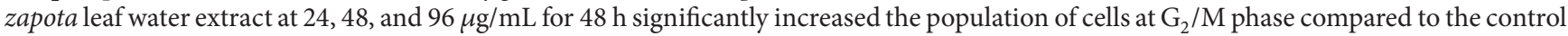
$(P<0.05)$. (d) Treatment with Manilkara zapota leaf water extract at 48 and $96 \mu \mathrm{g} / \mathrm{mL}$ significantly increased the population of cells at $\mathrm{G}_{0} / \mathrm{G}_{1}$ phase as compared to the control $(P<0.05)$ with a concomitant decrease of the $\mathrm{S}$ phase at $72 \mathrm{~h}$.

3.4. Treatment with Manilkara zapota Leaf Water Extract Induces Apoptosis in HepG2 Cells. Apoptosis is a crucial mechanism in the cancer chemoprevention and chemotherapy $[31,32]$. It acts as a silent cell death modality prior to the manifestation of malignancy [33]. Numerous chemotherapeutic drugs, including doxorubicin [34], tamoxifen [35], and cisplatin [36], inhibit neoplastic cells via cell cycle arrest and apoptosis induction. This suggests that natural products regardless of isolated bioactive compounds or crude extracts must stimulate the signals associated with cell death in order to serve as a potential agent in cancer therapy [37]. In order to validate Manilkara zapota leaf water extract induced apoptosis in HepG2 cells, Annexin V-FITC and propidium iodide fluorescence staining was measured quantitatively. The percentage of viable, early apoptotic cells, and late apoptotic and necrotic cells of untreated and Manilkara zapota leaf water extract treated HepG2 cells were measured by flow cytometry (Figure 5(a)).

Expectedly, we found no significant difference in early apoptotic cells between control and $48 \mu \mathrm{g} / \mathrm{mL}$ and $96 \mu \mathrm{g} / \mathrm{mL}$ of Manilkara zapota leaf water extract $(P>0.05)$. This result may reveal that the incubation time was too short to stimulate the early apoptotic cells (Figure 5(b)). Surprisingly, the percentage of late apoptotic and necrotic cells after 


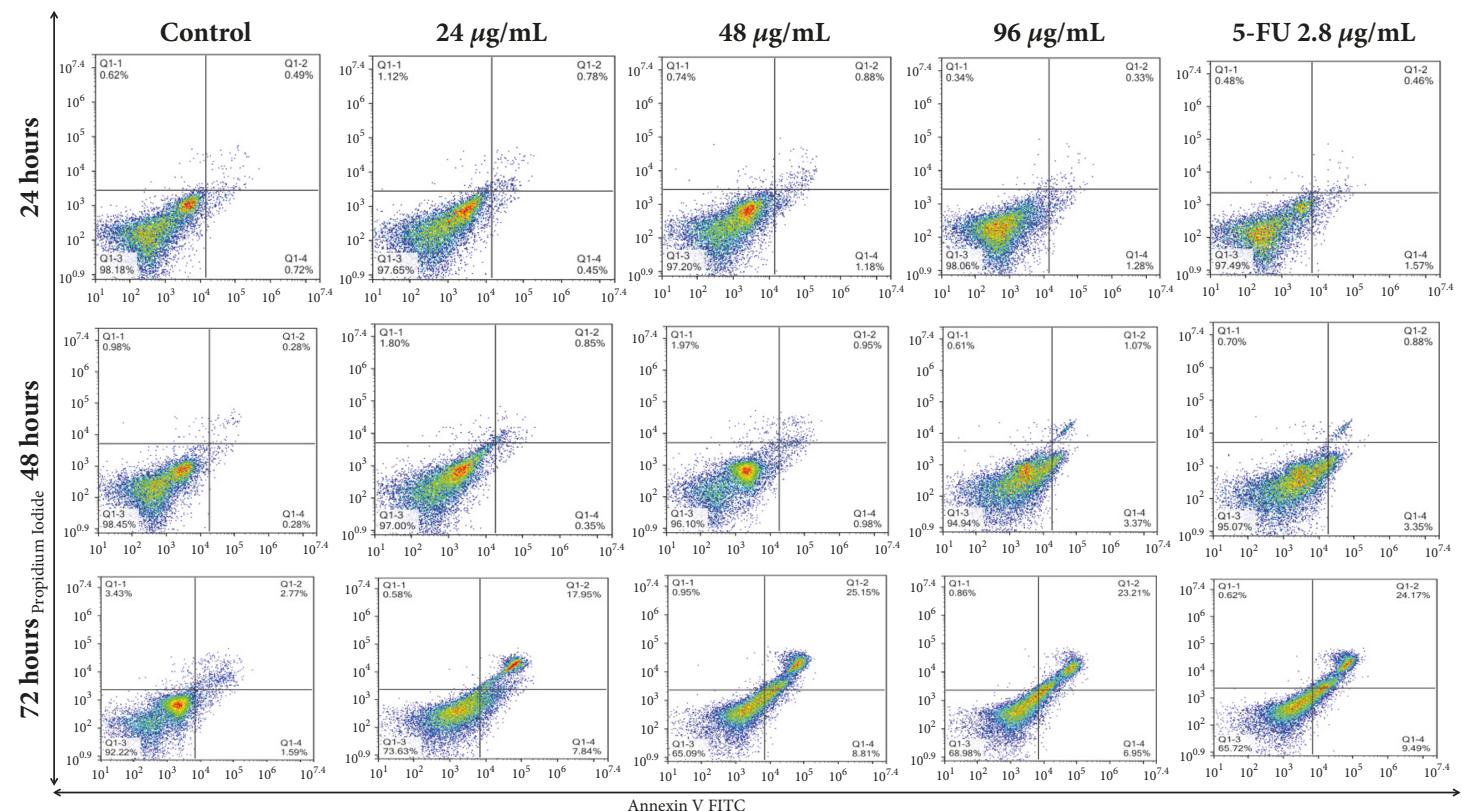

(a)

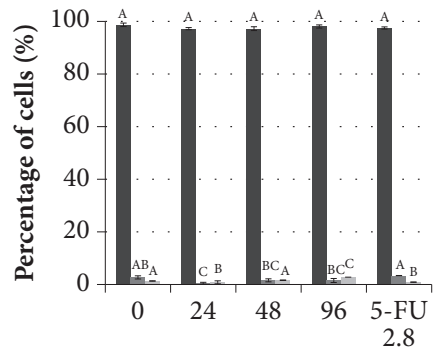

Concentration $(\mu \mathrm{g} / \mathrm{mL})$

- Viable

- Early apoptosis

Late apoptosis and necrosis

(b)

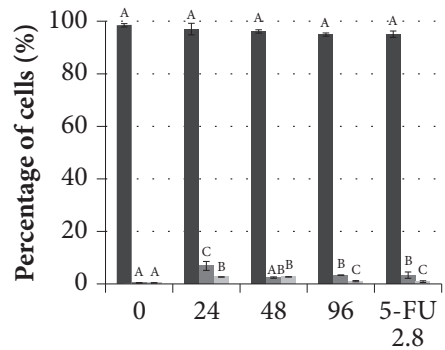

Concentration $(\mu \mathrm{g} / \mathrm{mL})$

- Viable

- Early apoptosis

$\square$ Late apoptosis and necrosis

(c)

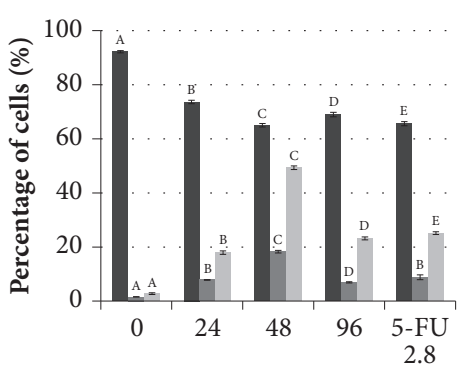

Concentration $(\mu \mathrm{g} / \mathrm{mL})$

- Viable

Early apoptosis

Late apoptosis and necrosis

(d)

Figure 5: The percentage of viable, apoptotic, and necrotic cells of (a) untreated cells and Manilkara zapota leaf water extract and 5Fluorouracil (5-FU) treated HepG2 cells for (b) $24 \mathrm{~h}$, (c) $48 \mathrm{~h}$, and (d) $72 \mathrm{~h}$ measured using the Annexin V-FITC and propidium iodide (PI) staining assay. Values are reported as mean $\pm \mathrm{SD}(\mathrm{n}=3)$. Value with different superscript letter indicates significant difference between groups by Tukey's test $(P<0.05)$. (b) There was no significant difference in early apoptotic cells between control and $48 \mu \mathrm{g} / \mathrm{mL}$ and $96 \mu \mathrm{g} / \mathrm{mL}$ of Manilkara zapota leaf water extract $(P>0.05)$. The percentage of late apoptotic and necrotic cells after treatment with $96 \mu \mathrm{g} / \mathrm{mL}(2.77 \%)$ of Manilkara zapota leaf water extract was significantly increased as compared to the control $(1.31 \%)(P<0.05)$. (c) Treatment with Manilkara zapota leaf water extract for 24 and $96 \mu \mathrm{g} / \mathrm{mL}$ at $48 \mathrm{~h}$ significantly increased the percentage of early apoptotic cells as compared to the control $(P<0.05)$. The percentage of late apoptotic and necrosis cells also significantly elevated at $48 \mathrm{~h}$, with a maximum effect observed at 24 and $48 \mu \mathrm{g} / \mathrm{mL}$ as compared to the control $(P<0.05)$. (d) Treatment with Manilkara zapota leaf water extract for $72 \mathrm{~h}$ significantly increased the percentage of early apoptotic cells at 24,48 , and $96 \mu \mathrm{g} / \mathrm{mL}(P<0.05)$. The percentages of late apoptotic and necrosis cells were significantly increased after treatment with Manilkara zapota leaf water extract for $72 \mathrm{~h}(P<0.05)$, with a maximum effect observed at $48 \mu \mathrm{g} / \mathrm{mL}$.

treatment with $96 \mu \mathrm{g} / \mathrm{mL}$ (2.77\%) of Manilkara zapota leaf water extract was significantly increased as compared to the control $(1.31 \%)(P<0.05)$. The high percentage of late apoptotic and necrosis cells observed in this particular group of cells could be due to the incubation time being too short, where the release of intracellular content of HepG2 after cellular membrane damage has surpassed the antioxidant capacity [38]. Nevertheless, the increased percentage of late apoptotic and necrotic cells after treatment with $96 \mu \mathrm{g} / \mathrm{mL}$ of Manilkara zapota leaf water extract in the present study remains to be elucidated.

Treatment with 24 and $96 \mu \mathrm{g} / \mathrm{mL}$ of Manilkara zapota leaf water extract for $48 \mathrm{~h}$ significantly increased the percentage of early apoptotic HepG2 cells as compared to the control $(P<0.05)$. The percentage of late apoptotic and necrotic cells also significantly elevated at $48 \mathrm{~h}$, with a maximum effect observed at 24 and $48 \mu \mathrm{g} / \mathrm{mL}$ as compared to the control $(P<0.05)$ (Figure 5(c)). Notably, treatment with 2.8 


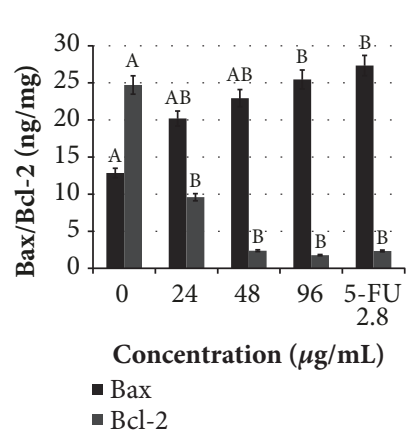

(a)

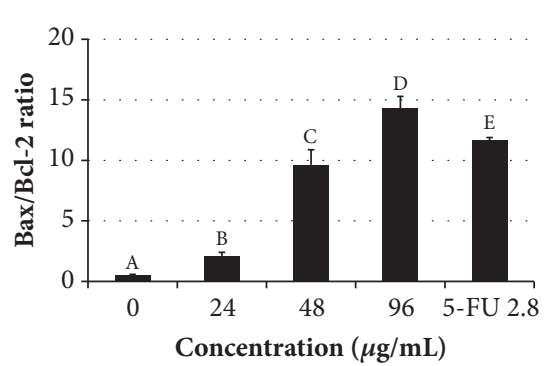

(b)

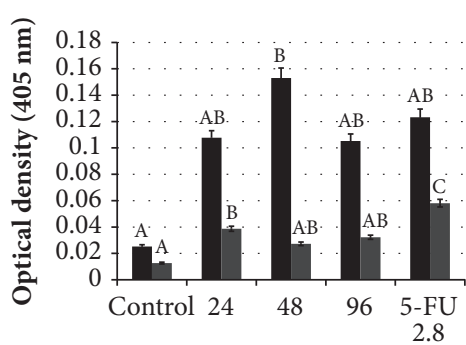

Concentration $(\mu \mathrm{g} / \mathrm{mL})$

- Caspase-3 - Caspase-8

(c)

FIGURE 6: Apoptotic activities in HepG2 cells after treatment with Manilkara zapota leaf water extract and 5-Fluorouracil (5-FU) for 72 h. Apoptotic protein expression of (a) Bax and Bcl-2, (b) Bax/Bcl-2 ratio, and (c) Caspase-3 and -8 activities in HepG2 cells treated with Manilkara zapota leaf water extract. Values are reported as mean \pm SD $(n=3)$. Value with different superscript letter indicates significant difference between groups by Tukey's test $(P<0.05)$. (a) Treatment with $96 \mu \mathrm{g} / \mathrm{mL}$ of Manilkara zapota leaf water extract significantly upregulated Bax protein level $(p<0.05)$. However, there was no significant difference between 24 and $48 \mu \mathrm{g} / \mathrm{mL}$ of Manilkara zapota leaf water extract $(P>0.05)$. Bcl-2 expression was significantly reduced after treatment with Manilkara zapota leaf water extract $(P<0.05)$. $(\mathrm{b})$ Treatment of HepG2 cells with Manilkara zapota leaf water extract significantly induced a dose-dependent increase in the Bax/Bcl-2 ratio $(P$ $<0.05)$. (c) The cells treated with Manilkara zapota leaf water extract at $48 \mu \mathrm{g} / \mathrm{mL}$ significantly increase the caspase-3 activity compared with the control (untreated cells) $(P<0.05)$. Treatment with Manilkara zapota leaf water extract at $24 \mu \mathrm{g} / \mathrm{mL}$ for $72 \mathrm{~h}$ also significantly upregulated the caspase- 8 activity $(P<0.05)$. However, there was no significant difference in caspase- 8 activity between 48 and $96 \mu \mathrm{g} / \mathrm{mL}(P>0.05)$.

$\mu \mathrm{g} / \mathrm{mL}$ of 5 -FU significantly increased the early apoptotic cells as compared to the control $(P<0.05)$ (Figure $5(\mathrm{c}))$. Furthermore, our data revealed that treatment of HepG2 cells with Manilkara zapota leaf water extract for $72 \mathrm{~h}$ significantly increased the percentage of early apoptotic cells at 24,48 , and $96 \mu \mathrm{g} / \mathrm{mL}$ for $7.84 \%, 18.30 \%$, and $6.95 \%$, respectively, as compared to the control $(P<0.05)$ (Figure 5(d)). This finding implied that Manilkara zapota leaf water extract might be used as a therapeutic agent for human liver cancer. Notably, the percentages of late apoptotic and necrotic cells were significantly increased after treatment with Manilkara zapota leaf water extract for $72 \mathrm{~h}(P<0.05)$, with a maximum effect observed at $48 \mu \mathrm{g} / \mathrm{mL}$ (Figure $5(\mathrm{~d})$ ). Based on the findings, leaf water extract of Manilkara zapota demonstrated the maximum apoptotic effect in HepG2 cells after $72 \mathrm{~h}$. Therefore, an incubation time of $72 \mathrm{~h}$ was selected for further analyses.

\subsection{Treatment with Manilkara zapota Leaf Water Extract} Activates the Bax and Downregulates Bcl-2 Protein Levels in HepG2 Cells. Bcl-2 family proteins regulate the intrinsic mitochondrial pathway. The $\mathrm{Bcl}-2$ family consists of the major apoptotic proteins which control the mitochondrial membrane permeability, such as antiapoptotic protein ( $\mathrm{Bcl}-$ 2) and proapoptotic protein (Bax) [39]. To explore the apoptotic protein expression and the underlying mechanism by which the Manilkara zapota leaf water extract induces apoptosis in HepG2 cells, Bax protein expression in HepG2 cells after induction with Manilkara zapota leaf water extract was evaluated. Our analysis revealed that treatment with 96 $\mu \mathrm{g} / \mathrm{mL}$ of Manilkara zapota leaf water extract significantly upregulated the Bax protein level $(P<0.05)$ (Figure 6(a)). Such a modulation may thus be involved in the proapoptotic effects of leaf water extract of Manilkara zapota and of bioactive constituents containing them. Taken together, the findings presented in this study suggested that Manilkara zapota leaf water extract initiates apoptosis in HepG2 cells through the mitochondrial intrinsic apoptotic pathway.

To confirm the apoptotic mechanisms induced by Manilkara zapota leaf water extract in HepG2 cells, Bcl2 protein expression was assessed. Our data revealed that Bcl-2 protein expression was decreased in a dose-dependent manner, with a maximum reduction observed at a concentration of $96 \mu \mathrm{g} / \mathrm{mL}$ (Figure $6(\mathrm{a})$ ). This result was further supported by Tor et al. [40], who found that Bcl-2 expression was reduced after treatment with ethyl acetate extract of Dillenia suffruticosa. Overall, our findings confirm that leaf water extract of Manilkara zapota induces several subcellular mechanisms favoring apoptosis. In further analysis, we demonstrated that Manilkara zapota leaf water extract resulted in a dose-dependent increase in the $\mathrm{Bax} / \mathrm{Bcl}-2$ ratio (Figure 6(b)). Such upregulation of Bax and downregulation of $\mathrm{Bcl}-2$ protein expression could lead to a major apoptotic response in HepG2 cells treated with leaf water extract of Manilkara zapota. Our data suggest that Manilkara zapota leaf water extract can induce apoptosis of HepG2 cells by regulating $\mathrm{Bax} / \mathrm{Bcl}-2$ ratio. Because our findings showed that the apoptotic response of HepG2 cells was modulated by $\mathrm{Bax} / \mathrm{Bcl}-2$ ratio, we further investigate the caspases- 3 and -8 activities.

\subsection{Treatment with Manilkara zapota Leaf Water Extract} Promotes Activation of Caspase-3 and -8 Activities in HepG2 Cells. Numerous molecular studies have shown that two critical apoptotic pathways, which are intrinsically mediated mitochondrial and extrinsic modulated death receptor pathways, can be triggered by caspases [41]. Caspases are crucial molecular targets in chemoprevention because these 


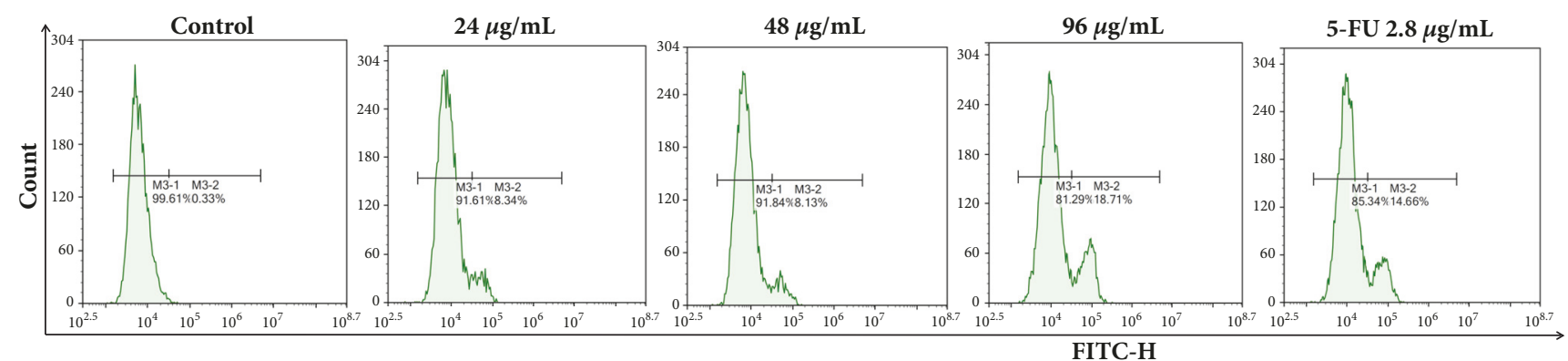

(a)

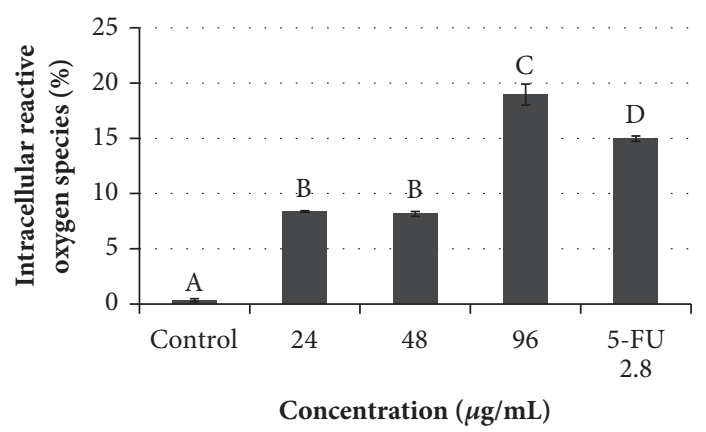

(b)

FIGURE 7: Determination of reactive oxygen species (ROS) in HepG2 cells. (a) Intracellular ROS in Manilkara zapota leaf water extract and 5-Fluorouracil (5-FU) treated HepG2 cells using dichlorodihydrofluorescein diacetate, measured using NovoCyte Flow Cytometer with NovoExpress ${ }^{\circledR}$ software. (b) Histogram presented the dichlorofluorescein (DCF) fluorescence intensity. Values are reported as mean \pm SD $(\mathrm{n}=$ 3). Value with different superscript letter indicates significant difference between groups by Tukey's test $(P<0.05)$. Treatment with Manilkara zapota leaf water extract at a concentration of 24,48 , and $96 \mu \mathrm{g} / \mathrm{mL}$ significantly elevated the ROS level compared to the control $(P<0.05)$.

processes contribute to apoptosis [42]. Thus, the activation of caspase-3 and -8 activities in HepG2 cells after exposure to Manilkara zapota leaf water extract was evaluated spectrophotometrically. To ascertain whether cell viability inhibition could be dependent on the stimulation of caspase3 and -8 , which serves as a central player in the modulation of apoptotic responses [43], the intracellular levels of caspase3 and -8 in HepG2 cells after treatment with Manilkara zapota leaf water extract were investigated. As presented in Figure 6(c), the cells treated with Manilkara zapota leaf water extract at $48 \mu \mathrm{g} / \mathrm{mL}$ significantly increased the caspase3 activity compared with the control (untreated cells) $(P<$ 0.05). In addition to the stimulation of caspase- 3 activity, caspase- 8 activity was also significantly upregulated after treatment with $24 \mu \mathrm{g} / \mathrm{mL}$ of Manilkara zapota leaf water extract for $72 \mathrm{~h}(P<0.05)$.

The quantification of caspase- 3 and -8 enzymatic activities confirmed the caspase activation by leaf water extract of Manilkara zapota. Indeed, caspase-3 was activated at the median inhibition concentration $(48 \mu \mathrm{g} / \mathrm{mL})$ of the treatment, while caspase- 8 seems activated at the lowest concentration $(24 \mu \mathrm{g} / \mathrm{mL})$ of the treatment. Collectively, this finding may suggest that an increase in caspase- 8 activity results in the activation of the downstream apoptotic executioner caspase- 3 and subsequently causes an activation of a molecular cascade of apoptosis in HepG2 cells. Taken together, our data indicate that Manilkara zapota leaf water extract inhibits the proliferation of liver cancer in vitro, which confirmed that the apoptosis induction by Manilkara zapota leaf water extract is caspase-mediated pathway.

\subsection{Treatment with Manilkara zapota Leaf Water Extract} Induces Reactive Oxygen Species Formation in HepG2 Cells. Previous studies have shown that biologically active compounds such as allicin combined with 5-Fluorouracil (5FU) are involved in oxidative stress [44]. We speculated that Manilkara zapota leaf water extract may induce apoptosis via increasing reactive oxygen species (ROS). To validate this hypothesis, the fluorochrome dichlorodihydrofluorescein diacetate (DCFH-DA) was used to measure the ROS level by flow cytometry. Our data revealed that reactive oxygen species (ROS) level was mainly present in the groups treated with leaf water extract of Manilkara zapota, with a maximum effect observed at a concentration of $96 \mu \mathrm{g} / \mathrm{mL}$ (Figures 7(a) and 7(b)). The observed effects were consistent with the results obtained by Cho et al. [45], who demonstrated that the elevation of ROS level triggers apoptosis in breast cancer cells. Further, chemotherapy agents have also been reported to induce oxidative stress and cause ROS generation [46]. Indeed, this finding indicates that excessive accumulation of ROS in the mitochondria may suppress the mitochondrial respiration chain and cause mitochondrial membrane rupture and apoptotic cell death [47, 48].

However, low ROS level was observed in untreated HepG2 cells (control). These data were further supported by 


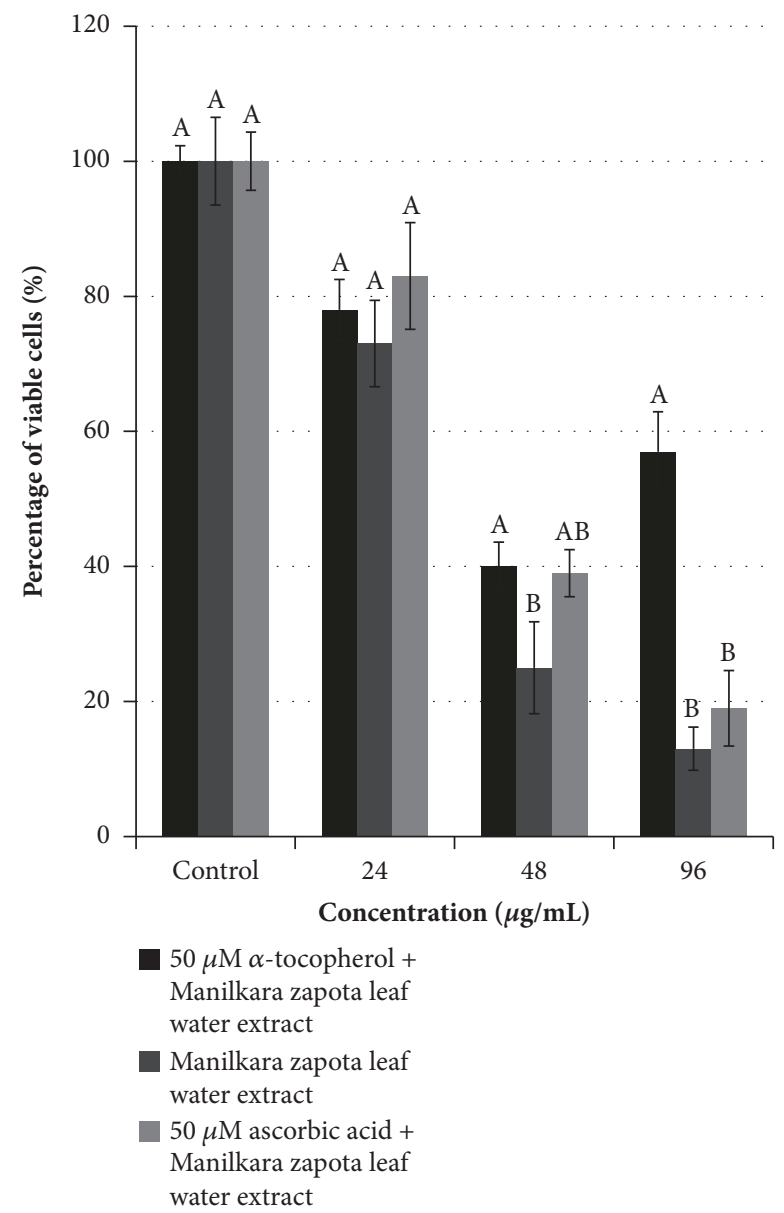

FIgURE 8: Determination on the involvement of ROS in Manilkara zapota leaf water extract in HepG2 cells. HepG2 cells were cotreated with $50 \mu \mathrm{M} \alpha$-tocopherol or ascorbic acid for $72 \mathrm{~h}$. Values are reported as mean $\pm \mathrm{SD}(\mathrm{n}=3)$. Value with different superscript letter indicates significant difference among the concentrations by Tukey's test $(P<0.05)$. At $96 \mu \mathrm{g} / \mathrm{mL}$, the cotreatment with $50 \mu \mathrm{M}$ antioxidant $\alpha$-tocopherol and Manilkara zapota leaf water extract significantly increased the viability of the cells to $57 \%(P<0.05)$. At $48 \mu \mathrm{g} / \mathrm{mL}$ of Manilkara zapota leaf water extract, cotreatment with $\alpha$-tocopherol significantly increased the viability of cells from $25 \%$ to $40 \%(P<$ $0.05)$.

Zou et al. [44], who found that low ROS level was mainly found in the untreated liver cancer (control). Importantly, this finding implies that low ROS levels may contribute to liver cancer, which contrasts its predicted role as a tumor suppressor [49].

To explore whether the cell death was mainly due to the ROS, the cells were cotreated with antioxidant ascorbic acid and $\alpha$-tocopherol. As shown in Figure 8 , the viability of the cells treated with Manilkara zapota leaf water extract alone at $96 \mu \mathrm{g} / \mathrm{mL}$ for $72 \mathrm{~h}$ was $13 \%$. The cotreatment with $50 \mu \mathrm{M}$ antioxidant $\alpha$-tocopherol and Manilkara zapota leaf water extract significantly increased the viability of the cells to $57 \%(P<0.05)$. At $48 \mu \mathrm{g} / \mathrm{mL}$ of Manilkara zapota leaf water extract, cotreatment with $\alpha$-tocopherol significantly increased the viability of cells from $25 \%$ to $40 \%((P<0.05)$. In comparison with Manilkara zapota leaf water extract alone, cells cotreated with $50 \mu \mathrm{M}$ ascorbic acid did not increase or decrease the viability of cells at all the tested concentrations (Figure 8).

Our present study demonstrated that ascorbic acid and $\alpha$-tocopherol did not block the reduction of cell viability at 24 and $48 \mu \mathrm{g} / \mathrm{mL}$ of Manilkara zapota leaf water extract, indicating that ROS may not be involved in the phenomenon at these two concentrations. However, at $96 \mu \mathrm{g} / \mathrm{mL}$ of Manilkara zapota leaf water extract, the cotreatment with $\alpha$ tocopherol significantly blocked the cell death, implying that high concentration of Manilkara zapota leaf water extract induced formation of ROS which played a central role in the induction of cell death in HepG2 cells. Taken together, these results suggest that a high concentration of Manilkara zapota leaf water extract induced the formation of ROS which played a crucial role in inducing cell death in HepG2 cells.

To gain a better understanding of this ROS-mediated apoptosis in HepG2 cells upon Manilkara zapota leaf water extract treatment, we evaluated the changes in the mRNA expression of extracellular signal-regulated kinase $1 / 2(E R K 1 / 2)$, protein kinase B $(A k t 1)$, c-Jun N-terminal kinase 1 (JNK1), inducible nitric oxide synthase (iNOS), and vascular endothelial growth factor A (VEGFA) using real-time polymerase chain reaction (PCR). Accumulating evidence suggests that ERKs and Akts have been implicated in cell proliferation $[12,50]$. Therefore, we are interested in finding whether apoptosis induction of Manilkara zapota leaf water extract in HepG2 cells observed in this study could be modulated by ERK1/2 and Aktl pathway. Based on the optimization, each gene of interest resulted in an efficiency of $89.6-108.7 \%$ (slope of -3.124 to -3.599 ). The melting curves analyses of the products demonstrated a single peak for each reference gene and target gene.

3.8. Treatment with Manilkara zapota Leaf Water Extract Inhibits ERK1/2 and Akt1 Response Pathway. Stimulation of ERK1/2 pathway is a crucial regulator in numerous cellular responses and cancer development [51]. To clarify the effects of Manilkara zapota leaf water extract in apoptosis of cancer cells, the expression levels of ERK1/2 were assessed. Realtime PCR analysis revealed that the mRNA expression of ERK1/2 was significantly downregulated at 48 and $96 \mu \mathrm{g} / \mathrm{mL}$ of Manilkara zapota leaf water extract treated HepG2 cells $(P<0.05)$ (Figure 9). These results suggest that treatment of HepG2 cells with Manilkara zapota leaf water extract may be associated with a marked increase in apoptotic cell death, as observed in Annexin V-FITC and propidium iodide fluorescence staining assay. Inhibition of ERK1/2 mRNA level was also found in the reduction of the proliferation of breast cancer cells [52], which is consistent with the finding in this study. Therefore, ERK1/2 mRNA level may play a crucial role in negatively regulating the ERK1/2 signaling pathway to inhibit the cell proliferation. Treatment with 48 and 96 $\mu \mathrm{g} / \mathrm{mL}$ of Manilkara zapota leaf water extract resulted in the downregulation of mRNA expression of ERK1/2. One of the possible reasons may be due to the efficiency of 


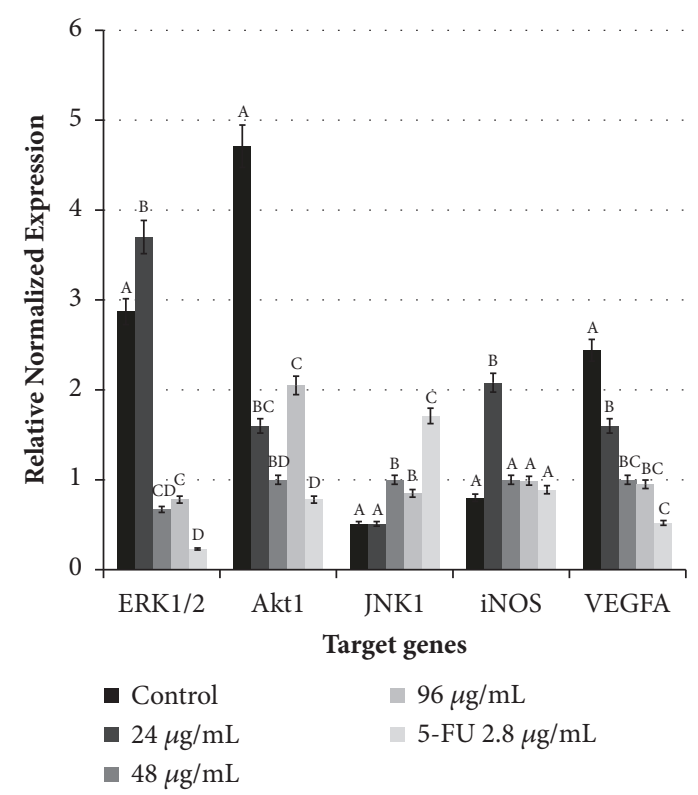

FIGURE 9: Expression of ERK1/2, Akt1, JNK1, iNOS, and VEGFA at mRNA levels in HepG2 cells incubated with Manilkara zapota leaf water extract and 5-Fluorouracil (5-FU) for $72 \mathrm{~h}$ analyzed using quantitative real-time PCR. Values are reported as mean \pm SD (n $=3$ ). Value with different superscript letter indicates significant difference between groups by Tukey's test $(P<0.05)$. The mRNA expression of ERK1/2 was significantly downregulated at 48 and 96 $\mu \mathrm{g} / \mathrm{mL}$ of Manilkara zapota leaf water extract treated HepG2 cells ( $P$ $<0.05)$. Manilkara zapota leaf water extract significantly upregulated the ERK1/2 mRNA level at $24 \mu \mathrm{g} / \mathrm{mL}(P<0.05)$. Akt1 expression was significantly downregulated in HepG2 cells treated with 24, 48, and $96 \mu \mathrm{g} / \mathrm{mL}$ of Manilkara zapota leaf water extract compared to the control $(P<0.05)$. Treatment with Manilkara zapota leaf water extract in a concentration of 48 and $96 \mu \mathrm{g} / \mathrm{mL}$ significantly upregulated the JNK1 mRNA level $(P<0.05)$. Treatment with $24 \mu \mathrm{g} / \mathrm{mL}$ of Manilkara zapota leaf water extract significantly upregulated the gene expression of $i$ NOS $(P<0.05)$. Manilkara zapota leaf water extract significantly reduced the gene expression of VEGFA compared to the untreated cells $(P<0.05)$. ACTB: betaactin; ERK1/2: extracellular signal-regulated kinase 1/2; GAPDH: glyceraldehyde-3-phosphate dehydrogenase; iNOS: inducible nitric oxide synthase; JNK1: c-Jun N-terminal kinase 1; VEGFA: vascular endothelial growth factor $\mathrm{A}$.

Manilkara zapota leaf water extract involved in the inhibition of ERK1/2 transcriptional activity reached with 48 and $96 \mu \mathrm{g} / \mathrm{mL}$.

However, upregulation of ERK1/2 mRNA level was noted in $24 \mu \mathrm{g} / \mathrm{mL}$ of Manilkara zapota leaf water extract (Figure 9), which is possibly associated with oxidative stress. Other than antioxidant defense, these effects also could be due to the cells counterbalance to the effect of oxidative stress via activation of the ERK1/2-dependent pathway. Collectively, our study suggests that Manilkara zapota leaf water extract could be a potent therapeutic agent against human hepatocellular carcinoma by phosphorylation of ERK1/2 expression. Further studies of the interactions and the underlying mechanisms in Manilkara zapota leaf water extract induced apoptosis may pave the way to the knowledge of apoptotic network.
To further verify whether Manilkara zapota leaf water extract could suppress the proliferation of HepG2 cells, we determined the chemoprevention mechanism of Akt1 on Manilkara zapota leaf water extract in this model. Akt is a serine-threonine kinase that controls the balance between apoptosis and survival. Akt1 expression was significantly downregulated in Manilkara zapota leaf water extract treated HepG2 cells compared to the control $(P<0.05)$, with a maximum reduction observed at a concentration of $48 \mu \mathrm{g} / \mathrm{mL}$ (Figure 9), suggesting the involvement of Aktl pathway in Manilkara zapota leaf water extract induced apoptosis. Research evidence found that apoptosis in cancer cells was associated with the suppression of Akt signaling pathway after treatment with retinoic-acid or Wogonin [53]. A similar finding was also reported by Huang et al. [54], who found that polyphenol derived from fruits and vegetables inhibited the migration of lung cancer via suppression of Akt activity. In line with the previous observations, our present study also demonstrated that Manilkara zapota leaf water extract downregulated the transcriptional activity of $A k t 1$. Deregulation of Akt signaling pathway in cancer cells has become one of the therapeutic targets in the search of potential cancer treatment [55]. Therefore, this finding implies that Manilkara zapota leaf water extract has a potential in the treatment of liver cancer.

\subsection{Treatment with Manilkara zapota Leaf Water Extract} Induces JNK1 mRNA Level in HepG2 Cells. With regard to other transcription factors involved in cancer development, JNK is likely to be involved in coordination with oxidative stress. The expression of JNK is a stress-responsive kinase. Upregulation of JNK has been demonstrated to induce apoptosis in various cancers [56,57]. The expression of JNK1 was abundantly present in the concentrations of 48 and 96 $\mu \mathrm{g} / \mathrm{mL}$ of Manilkara zapota leaf water extract (Figure 9). The activation of JNK1 in the concentrations of 48 and $96 \mu \mathrm{g} / \mathrm{mL}$ implied that higher concentration of bioactive components in the Manilkara zapota leaf water extract may confer better functional properties in the regulation of JNK1. This finding was consistent with the study reported by Palit et al. [58], who demonstrated that the expression of JNK was activated upon treatment with hesperetin, a flavanone glycoside predominantly contained in citrus fruit, subsequently triggering apoptosis. However, there was no significant difference in JNK1 expression between control and $24 \mu \mathrm{g} / \mathrm{mL}$ of Manilkara zapota leaf water extract $(P>$ $0.05)$. This result may reveal that the bioactive constituents present in this concentration are insufficient to stimulate the JNK1. Collectively, this study showed the transcriptional activation of JNK1 following treatment with Manilkara zapota leaf water extract, suggesting that the activation of JNK1 could be attributed to bioactive constituents present in Manilkara zapota leaf water extract (unpublished data), subsequently triggering apoptosis and inhibiting proliferation in HepG2 cells. Therefore, our results implied that there is an important link between transcriptional regulation and apoptosis modulation. Taken together, activation of JNK1 mRNA level in Manilkara zapota leaf water extract treated HepG2 cells may play a crucial role in regulating the apoptosis. 
3.10. Treatment with Manilkara zapota Leaf Water Extract Upregulates iNOS mRNA Level in HepG2 Cells. In addition to the effects observed in ERK1/2/Akt1/JNK1 signaling pathways, the roles of $i N O S$ in the inhibition of liver cancer elicited by Manilkara zapota leaf water extract require further elucidation. Thus, the mRNA expression of $i N O S$ in HepG2 cells was evaluated to determine whether Manilkara zapota leaf water extract could modulate the iNOS at the mRNA level. In the current study, we found a low mRNA expression of iNOS in the untreated HepG2 cells. The data presented in this study exhibited that treatment with $24 \mu \mathrm{g} / \mathrm{mL}$ of Manilkara zapota leaf water extract significantly upregulated the gene expression of $i N O S(P<0.05)$ (Figure 9). The upregulation of $i N O S$ mRNA expression in the present study was consistent with the findings reported by Radomski et al. [59], who observed that the expression of iNOS was negatively associated with metastasis in human-murine melanoma (K1735) and colon cancer cells. Likewise, the study reported by Tan et al. [60] also found that iNOS overexpression inhibited the proliferation of colon tumor. Therefore, the upregulation of iNOS at the mRNA level may play a crucial role in the suppression of growth and induction of apoptosis in HepG2 cells. These findings suggest that Manilkara zapota leaf water extract reduced cancer proliferation via an anti-inflammatory mechanism involving iNOS expression. Notably, no significant difference was observed after treatment with 48 and $96 \mu \mathrm{g} / \mathrm{mL}$ of Manilkara zapota leaf water extract $(P>$ 0.05) (Figure 9). These findings demonstrated that Manilkara zapota leaf water extract did not block the reduction of cell viability at 48 and $96 \mu \mathrm{g} / \mathrm{mL}$ in this signaling pathway.

3.11. Treatment with Manilkara zapota Leaf Water Extract Attenuates VEGFA mRNA Expression in HepG2 Cells. Because Manilkara zapota leaf water extract suppresses ERK1/2 and Akt1 expression, the susceptibility of HepG 2 cells to Manilkara zapota leaf water extract might also be due to the inhibition of metastasis via the suppression of VEGFA mRNA level. Thus, the mRNA level of VEGFA in Manilkara zapota leaf water extract was investigated to determine whether the extract could modulate VEGFA expression. The overall analysis indicated that untreated HepG2 cells presented the highest VEGFA expression compared with the groups treated with leaf water extract of Manilkara zapota (Figure 9). A significant reduction in the gene expression of VEGFA was also observed in the HepG2 cells treated with Manilkara zapota leaf water extract compared to the untreated cells ( $P$ $<0.05$ ) (Figure 9). Our study revealed that treatment with Manilkara zapota leaf water extract resulted in the inhibition of VEGFA expression, and the maximum effect was obtained with $96 \mu \mathrm{g} / \mathrm{mL}$ of Manilkara zapota leaf water extract. These data implied that Manilkara zapota leaf water extract has the potential to inhibit VEGFA expression. These findings indicate that Manilkara zapota leaf water extract might be involved in the suppression of metastasis or migration in HepG2 cells. The data presented in this study highlights the fact that Manilkara zapota leaf water extract contains potential antitumor and metastatic components for liver cancer cells. This result was consistent with the study obtained by Moyle et al. [61], who reported the potent inhibition of VEGF signaling by polyphenols. Such finding highlights the fundamental idea that polyphenol fraction can impact the angiogenic functions and inflammation. These data demonstrated that VEGFA is a key molecular target for Manilkara zapota leaf water extract which potently suppresses VEGF signaling and angiogenesis.

Phytochemical screening is one of the methods that have been employed to evaluate the antioxidant constituents in a plant sample. Of all phytochemicals, only flavonoids and saponins were present in Manilkara zapota leaf water extract in the qualitative analysis of phytochemicals. None of the steroids, triterpenoids, and phlobatannins was detected in the extract (unpublished data). The effects observed in this study could be due to the synergistic/additive effects of the phytochemicals such as flavonoids, saponins, and phenolic compounds [mainly gallic acid $(23.11 \pm 2.15 \mu \mathrm{g} / \mathrm{g})$, caffeic acid $(3.04 \pm 0.12 \mu \mathrm{g} / \mathrm{g})$, and vanillic acid (5.90 \pm 0.71 $\mu \mathrm{g} / \mathrm{g})]$ and antioxidant activity as evaluated using $\beta$-carotene bleaching test $(49.94 \pm 10.60 \%)$ and 1,1-diphenyl-2-picrylhydrazyl (DPPH) radical scavenging capacity assays $(0.24 \pm$ $0.02 \mathrm{mg} / \mathrm{mL}$ ) in the extract (unpublished data).

With regard to the present study, inhibition of the progression of liver cancer cells via multiple signaling pathways mediated apoptosis could be attributed by the presence of bioactive compounds in the Manilkara zapota leaf water extract. Importantly, our previous study also presented the safety of this extract in regard to the cell growth of noncancerous cells, such as mouse fibroblast (BALB/c 3T3) cell line (unpublished data). Manilkara zapota leaf water extract did not affect the cell viability of BALB/c 3T3 cell lines in the tested range, as the survival was consistently greater than $80 \%$ or similar to untreated BALB/c 3T3 cell lines. Therefore, Manilkara zapota leaf water extract might be a potential anticancer agent that can be used to suppress the development of liver cancer.

\section{Conclusions}

This study clearly showed that Manilkara zapota leaf water extract offers great potential against liver cancer via modulation of multiple signaling pathways. Our study demonstrated that Manilkara zapota leaf water extract upregulates $J N K 1$ and $i N O S$ and transcriptional downregulation of $E R K 1 / 2$, $A k t 1$, and VEGFA expression implies the potential use of Manilkara zapota leaf water extract in future applications to combat liver cancer. However, to fully elucidate the potential of Manilkara zapota leaf water extract as an anticancer agent, further in-depth studies such as animal experimentation are needed to provide valuable insights to develop it as a therapeutic approach for the treatment of human hepatocellular carcinoma and other human malignancies. Altogether, this finding provides substantial evidence that Manilkara zapota leaf water extract induces early apoptosis in HepG2 cells via modulation of intrinsic mitochondrial pathways and suppression of metastasis. Taken together, our data suggested that Manilkara zapota leaf water extract has noteworthy apoptotic potentials via the regulation of ERK1/2/Akt1/JNK1 transcriptional activity. 


\section{Data Availability}

The data used to support the findings of this study are included within the article.

\section{Conflicts of Interest}

The authors declare that they have no conflicts of interest regarding the publication of this article.

\section{Authors' Contributions}

Bee Ling Tan contributed to the study design; conducted the lab work, data acquisition, and data analysis and interpretation; and wrote the manuscript. Mohd Esa Norhaizan participated in the study design, advised lab work, and commented on the final version of the manuscript. Lee Chin Chan participated in flow cytometry analysis and data interpretation. All authors read and approved the final manuscript.

\section{Acknowledgments}

We would like to thank Ministry of Science, Technology, and Innovation (MOSTI), Malaysia (project no. 02-01-04-SF2141) for financial support.

\section{References}

[1] World Health Organization, "Liver CancerEstimated Incidence, Mortality and Prevalence Worldwide in 2012," 2015, http://globocan.iarc.fr/old/FactSheets/cancers/liver-new.asp.

[2] L. Shengquan and H. L. Sze Ngong, "Design of low-molecularweight prodrugs for targeted delivery of anticancer agents," in Proceedings of the 3rd International Conference and Exhibition on Pharmaceutics and Novel Drug Delivery Systems, Hilton, Chicago/Northbrook, USA, 2013.

[3] P. Fitzmorris, M. Shoreibah, B. S. Anand, and A. K. Singal, "Management of hepatocellular carcinoma," Journal of Cancer Research and Clinical Oncology, vol. 141, no. 5, pp. 861-876, 2015.

[4] J.-H. Zhong, Q.-L. Zhong, L.-Q. Li, and H. Li, "Adjuvant and chemopreventive therapies for resectable hepatocellular carcinoma: a literature review," Tumor Biology, vol. 35, no. 10, pp. 9459-9468, 2014.

[5] C. T. Shearn, P. Reigan, and D. R. Petersen, "Inhibition of hydrogen peroxide signaling by 4 -hydroxynonenal due to differential regulation of Aktl and Akt2 contributes to decreases in cell survival and proliferation in hepatocellular carcinoma cells," Free Radical Biology \& Medicine, vol. 53, no. 1, pp. 1-11, 2012.

[6] Z. Wang, H. Zhang, X. Xu et al., "BFGF inhibits ER stress induced by ischemic oxidative injury via activation of the PI3K/Akt and ERK1/2 pathways," Toxicology Letters, vol. 212, no. 2, pp. 137-146, 2012.

[7] N. P. Judd, A. E. Winkler, O. Murillo-Sauca et al., "ERK1/2 regulation of CD44 modulates oral cancer aggressiveness," Cancer Research, vol. 72, no. 1, pp. 365-374, 2012.

[8] Y. R. Chin and A. Toker, "The actin-bundling protein palladin is an Aktl-specific substrate that regulates breast cancer cell migration," Molecular Cell, vol. 38, no. 3, pp. 333-344, 2010.
[9] A. S. Dhillon, S. Hagan, O. Rath, and W. Kolch, "MAP kinase signalling pathways in cancer," Oncogene, vol. 26, no. 22, pp. 3279-3290, 2007.

[10] E. K. Kim and E.-J. Choi, "Compromised MAPK signaling in human diseases: an update," Archives of Toxicology, vol. 89, no. 6, pp. 867-882, 2015.

[11] W. Lim, S. Park, F. W. Bazer, and G. Song, "Apigenin reduces survival of choriocarcinoma cells by inducing apoptosis via the PI3K/AKT and ERK1/2 MAPK pathways," Journal of Cellular Physiology, vol. 231, no. 12, pp. 2690-2699, 2016.

[12] N. Singh, D. Zaidi, H. Shyam, R. Sharma, and A. K. Balapure, "Polyphenols sensitization potentiates susceptibility of mcf-7 and mda mb-231 cells to centchroman," PLOS ONE, vol. 7, no. 6, 2012.

[13] S. Prasad, V. R. Yadav, R. Kannappan, and B. B. Aggarwal, "Ursolic acid, a pentacyclin triterpene, potentiates trail-induced apoptosis through p53-independent up-regulation of death receptors: evidence for the role of reactive oxygen species and JNK," The Journal of Biological Chemistry, vol. 286, no. 7, pp. 5546-5557, 2011.

[14] D. Kim, L. D. Kubzansky, A. Baccarelli et al., "Psychological factors and DNA methylation of genes related to immune/inflammatory system markers: the VA Normative Aging Study," BMJ Open, vol. 6, no. 1, p. e009790, 2016.

[15] J. Y. Park, M. S. Shin, S. N. Kim et al., "Polysaccharides from Korean Citrus hallabong peels inhibit angiogenesis and breast cancer cell migration," International Journal of Biological Macromolecules, vol. 85, pp. 522-529, 2016.

[16] R. L. G. Lecaros, L. Huang, T.-C. Lee, and Y.-C. Hsu, "Nanoparticle delivered VEGF-A siRNA enhances photodynamic therapy for head and neck cancer treatment," Molecular Therapy, vol. 24, no. 1, pp. 106-116, 2016.

[17] A. Ghani, Medicinal plants of Bangladesh: Chemical Constituents and Uses, Asiatic Society of Bangladesh, Dhaka, Bangladesh, 2003.

[18] V. Kothari and S. Seshadri, "In vitro antibacterial activity in seed extracts of Manilkara zapota, Anona squamosa and Tamarindus indica," Biological Research, vol. 43, no. 2, pp. 165-168, 2010.

[19] N. M. Fayek, A. R. Abdel Monem, M. Y. Mossa, M. R. Meselhy, and A. H. Shazly, "Chemical and biological study of Manilkara zapota (L.) Van Royen leaves (Sapotaceae) cultivated in Egypt," Pharmacognosy Research, vol. 4, no. 2, pp. 85-91, 2012.

[20] M. Abu Osman, M. Abdul Aziz, M. Rowshanul Habib, and M. Rezaul Karim, "Antimicrobial Investigation on Manilkara zapota (L.) P. Royen," International Journal of Drug Development and Research, vol. 3, no. 1, pp. 185-190, 2011.

[21] M. A. Khalek, Z. Khatun, M. Rowshanul Habib, and M. Rezaul Karim, "Antitumor activity of Manilkara zapota (L.) fruits against Ehrlich ascites carcinoma in mice," Biologija, vol. 61, no. 3-4, 2015.

[22] B. L. Tan, M. E. Norhaizan, H. J. Suhaniza, C. C. Lai, S. Norazalina, and K. Roselina, "Antioxidant properties and antiproliferative effect of brewers' rice extract (temukut) on selected cancer cell lines," International Food Research Journal, vol. 20, no. 5, pp. 2117-2124, 2013.

[23] K. H. Leong, C. Y. Looi, X.-M. Loong et al., "Cycloart-24-ene26-ol-3-one, a new cycloartane isolated from leaves of Aglaia exima triggers tumour necrosis factor-receptor 1-mediated caspase-dependent apoptosis in colon cancer cell line," PLoS ONE, vol. 11, no. 4, 2016.

[24] V. K. Sirohi, P. Popli, P. Sankhwar et al., "Curcumin exhibits anti-tumor effect and attenuates cellular migration via Slit-2 
mediated down-regulation of SDF-1 and CXCR4 in endometrial adenocarcinoma cells," The Journal of Nutritional Biochemistry, vol. 44, pp. 60-70, 2017.

[25] P. Prayong, S. Barusrux, and N. Weerapreeyakul, "Cytotoxic activity screening of some indigenous Thai plants," Fitoterapia, vol. 79, no. 7-8, pp. 598-601, 2008.

[26] C. M. Furtado, M. C. Marcondes, M. Sola-Penna, M. L. S. de Souza, and P. Zancan, "Clotrimazole preferentially inhibits human breast cancer cell proliferation, viability and glycolysis," PLoS ONE, vol. 7, no. 2, 2012.

[27] N. Vidula and H. S. Rugo, "Cyclin-dependent kinase 4/6 inhibitors for the treatment of breast cancer: a review of preclinical and clinical data," Clinical Breast Cancer, vol. 16, no. 1, pp. 8-17, 2016.

[28] L. Zhao, H.-C. Miao, W.-J. Li et al., "LW-213 induces G2/M cell cycle arrest through AKT/GSK3 $\beta / \beta$-catenin signaling pathway in human breast cancer cells," Molecular Carcinogenesis, vol. 55, no. 5, pp. 778-792, 2016.

[29] M. Barton-Burke and G. M. Wilkes, Cancer Therapies, Jones and Barlett's books, USA, 10th edition, 2006.

[30] S. Ozawa, Y. Sugiyama, Y. Mitsuhashi, T. Kobayashi, and M. Inaba, "Cell killing action of cell cycle phase-non-specific antitumor agents is dependent on concentration-time product," Cancer Chemotherapy and Pharmacology, vol. 21, no. 3, pp. 185190, 1988.

[31] K. Wang, C. Zhang, J. Bao et al., "Synergistic chemopreventive effects of curcumin and berberine on human breast cancer cells through induction of apoptosis and autophagic cell death," Scientific Reports, vol. 6, no. 1, 2016.

[32] A. Bishayee, A. Mandal, P. Bhattacharyya, and D. Bhatia, "Pomegranate exerts chemoprevention of experimentally induced mammary tumorigenesis by suppression of cell proliferation and induction of apoptosis," Nutrition and Cancer, vol. 68, no. 1, pp. 120-130, 2016.

[33] B. N. Singh, S. Shankar, and R. K. Srivastava, "Green tea catechin, epigallocatechin-3-gallate (EGCG): mechanisms, perspectives and clinical applications," Biochemical Pharmacology, vol. 82, no. 12, pp. 1807-1821, 2011.

[34] A.-M. Meredith and C. R. Dass, "Increasing role of the cancer chemotherapeutic doxorubicin in cellular metabolism," Journal of Pharmacy and Pharmacology, vol. 68, no. 6, pp. 729-741, 2016.

[35] W. Li, X. Shi, Y. Xu, J. Wan, S. Wei, and R. Zhu, “Tamoxifen promotes apoptosis and inhibits invasion in estrogen-positive breast cancer MCF-7 cells," Molecular Medicine Reports, vol. 16, no. 1, pp. 478-484, 2017.

[36] M. Matsumoto, W. Nakajima, M. Seike, A. Gemma, and N. Tanaka, "Cisplatin-induced apoptosis in non-small-cell lung cancer cells is dependent on Bax- and Bak-induction pathway and synergistically activated by BH3-mimetic ABT-263 in p53 wild-type and mutant cells," Biochemical and Biophysical Research Communications, vol. 473, no. 2, pp. 490-496, 2016.

[37] P. Tewary, A. A. L. Gunatilaka, and T. J. Sayers, "Using natural products to promote caspase-8-dependent cancer cell death," Cancer Immunology, Immunotherapy, vol. 66, no. 2, pp. 223-231, 2017.

[38] R. I. Salganik, "The benefits and hazards of antioxidants: controlling apoptosis and other protective mechanisms in cancer patients and the human population," Journal of the American College of Nutrition, vol. 20, supplement 5, pp. 464S-472S, 2001.

[39] M. A. Rahman, M. T. Sultan, and M. R. Islam, "Apoptosis and cancer: insights molecular mechanisms and treatments,"
International Journal of Biomolecular and Biomedicine, vol. 2, no. 1, pp. 1-16, 2012.

[40] Y. S. Tor, L. S. Yazan, J. B. Foo et al., "Induction of apoptosis in MCF-7 cells via oxidative stress generation, mitochondriadependent and caspase-independent pathway by ethyl acetate extract of Dillenia suffruticosa and its chemical profile," PLoS ONE, vol. 10, no. 6, 2015.

[41] M. Ocker and M. Höpfner, "Apoptosis-modulating drugs for improved cancer therapy," European Surgical Research, vol. 48, no. 3, pp. 111-120, 2012.

[42] D. Xu, L. Li, L. Liu et al., "Polychlorinated biphenyl quinone induces mitochondrial-mediated and caspase-dependent apoptosis in HepG2 cells," Environmental Toxicology, vol. 30, no. 9, pp. 1063-1072, 2015.

[43] A. Mohammadi, B. Mansoori, M. Aghapour, and B. Baradaran, "Urtica dioica dichloromethane extract induce apoptosis from intrinsic pathway on human prostate cancer cells (PC3)," Cellular and Molecular Biology, vol. 62, no. 3, pp. 78-83, 2016.

[44] X. Zou, J. Liang, J. Sun et al., "Allicin sensitizes hepatocellular cancer cells to anti-tumor activity of 5-fluorouracil through ROS-mediated mitochondrial pathway," Journal of Pharmacological Sciences, vol. 131, no. 4, pp. 233-240, 2016.

[45] S.-G. Cho, S.-M. Woo, and S.-G. Ko, "Butein suppresses breast cancer growth by reducing a production of intracellular reactive oxygen species," Journal of Experimental \& Clinical Cancer Research, vol. 33, no. 1, article no. 51, 2014.

[46] V. J. Victorino, L. Pizzatti, P. Michelletti, and C. Panis, "Oxidative stress, redox signaling and cancer chemoresistance: putting together the pieces of the puzzle," Current Medicinal Chemistry, vol. 21, no. 28, pp. 3211-3226, 2014.

[47] A. Tsuchiya, Y. Kaku, T. Nakano, and T. Nishizaki, "Diarachidonoylphosphoethanolamine induces apoptosis of malignant pleural mesothelioma cells through a Trx/ASK1/p38 MAPK pathway," Journal of Pharmacological Sciences, vol. 129, no. 3, pp. 160-168, 2015.

[48] V. Gogvadze, S. Orrenius, and B. Zhivotovsky, "Mitochondria as targets for chemotherapy," Apoptosis, vol. 14, no. 4, pp. 624-640, 2009.

[49] S. Prasad, S. C. Gupta, and A. K. Tyagi, "Reactive oxygen species (ROS) and cancer: role of antioxidative nutraceuticals," Cancer Letters, vol. 387, pp. 95-105, 2017.

[50] Y. Sun, W. Z. Liu, T. Liu, X. Feng, N. Yang, and H. F. Zhou, "Signaling pathway of MAPK/ERK in cell proliferation, differentiation, migration, senescence and apoptosis," Journal of Receptors and Signal Transduction, 2015.

[51] G. Romano, M. Acunzo, M. Garofalo et al., "MiR-494 is regulated by ERK1/2 and modulates TRAIL-induced apoptosis in non-small-cell lung cancer through BIM down-regulation," Proceedings of the National Acadamy of Sciences of the United States of America, vol. 109, no. 41, pp. 16570-16575, 2012.

[52] H. Atmaca, "Effects of galium aparine extract on the angiogenic cytokines and ERK1/2 proteins in human breast cancer cells," Celal Bayar Üniversitesi Fen Bilimleri Dergisi, vol. 14, no. 1, pp. 171-179, 2018.

[53] K. F. Huang, G. D. Zhang, Y. Q. Huang, and Y. Diao, "Wogonin induces apoptosis and down-regulates survivin in human breast cancer MCF-7 cells by modulating PI3K-AKT pathway," International Immunopharmacology, vol. 12, no. 2, pp. 334-341, 2012.

[54] H.-C. Huang, L.-L. Tsai, J.-P. Tsai et al., "Licochalcone A inhibits the migration and invasion of human lung cancer cells via 
inactivation of the Akt signaling pathway with downregulation of MMP-1/-3 expression," Tumor Biology, vol. 35, no. 12, pp. 12139-12149, 2014.

[55] A. Bahrami, M. Khazaei, M. Hasanzadeh et al., "Therapeutic Potential of Targeting PI3K/AKT Pathway in Treatment of Colorectal Cancer: Rational and Progress," Journal of Cellular Biochemistry, vol. 119, no. 3, pp. 2460-2469, 2018.

[56] S. Zhang, L. Shi, H. Ma et al., "Dihydroartemisinin induces apoptosis in human gastric cancer cell line BGC-823 through activation of JNK1/2 and p38 MAPK signaling pathways," Journal of Receptors and Signal Transduction, vol. 37, no. 2, pp. 174-180, 2017.

[57] H. Konishi, M. Fujiya, H. Tanaka et al., "Probiotic-derived ferrichrome inhibits colon cancer progression via JNK-mediated apoptosis," Nature Communications, vol. 7, 2016.

[58] S. Palit, S. Kar, G. Sharma, and P. K. Das, "Hesperetin induces apoptosis in breast carcinoma by triggering accumulation of ROS and activation of ASK1/JNK pathway," Journal of Cellular Physiology, vol. 230, no. 8, pp. 1729-1739, 2015.

[59] M. W. Radomski, D. C. Jenkins, L. Holmes, and S. Moneada, "Human colorectal adenocarcinoma cells: differential nitric oxide synthesis determines their ability to aggregate platelets," Cancer Research, vol. 51, no. 22, pp. 6073-6078, 1991.

[60] B. L. Tan, M. E. Norhaizan, K. Huynh, S. K. Yeap, H. Hazilawati, and K. Roselina, "Brewers' rice modulates oxidative stress in azoxymethane-mediated colon carcinogenesis in rats," World Journal of Gastroenterology, vol. 21, no. 29, pp. 8826-8835, 2015.

[61] C. W. A. Moyle, A. B. Cerezo, M. S. Winterbone et al., "Potent inhibition of VEGFR-2 activation by tight binding of green tea epigallocatechin gallate and apple procyanidins to VEGF: Relevance to angiogenesis," Molecular Nutrition \& Food Research, vol. 59, no. 3, pp. 401-412, 2015. 


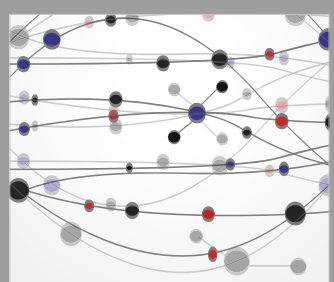

The Scientific World Journal
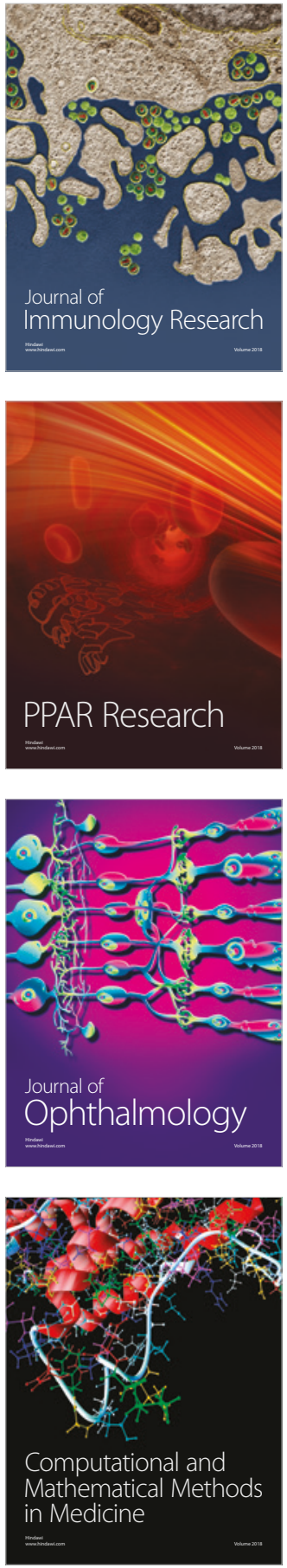

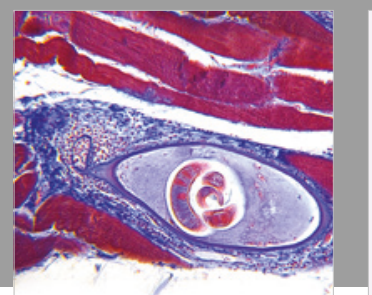

Gastroenterology Research and Practice

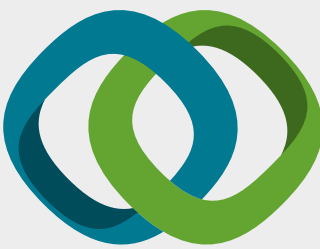

\section{Hindawi}

Submit your manuscripts at

www.hindawi.com
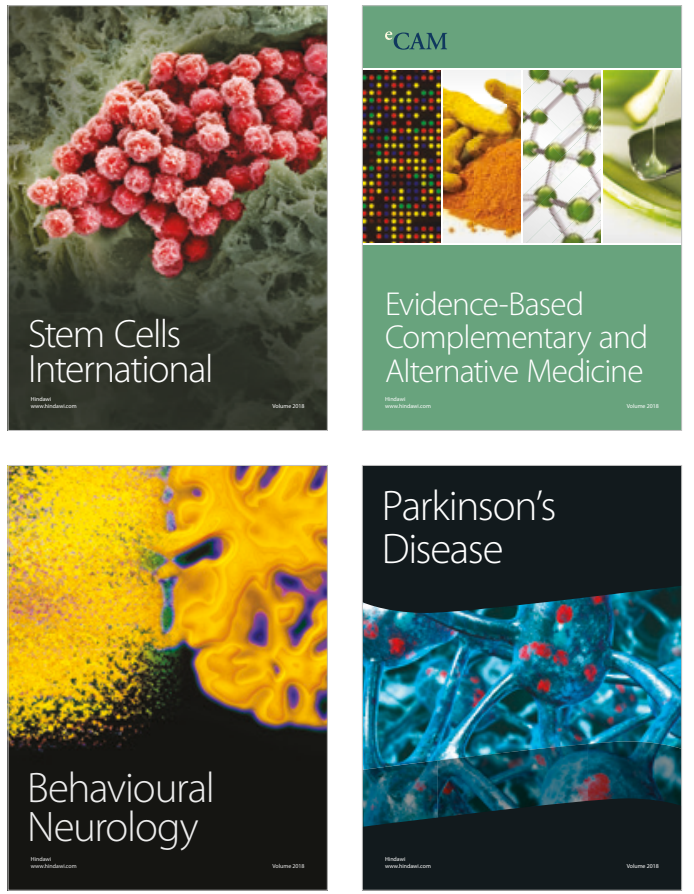

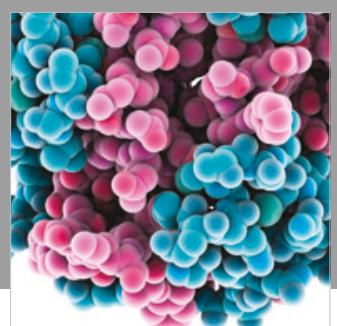

ournal of

Diabetes Research

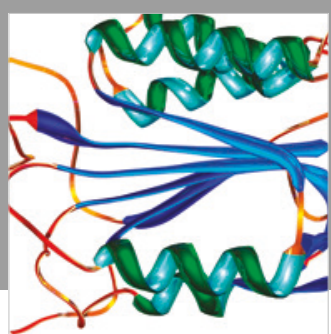

Disease Markers
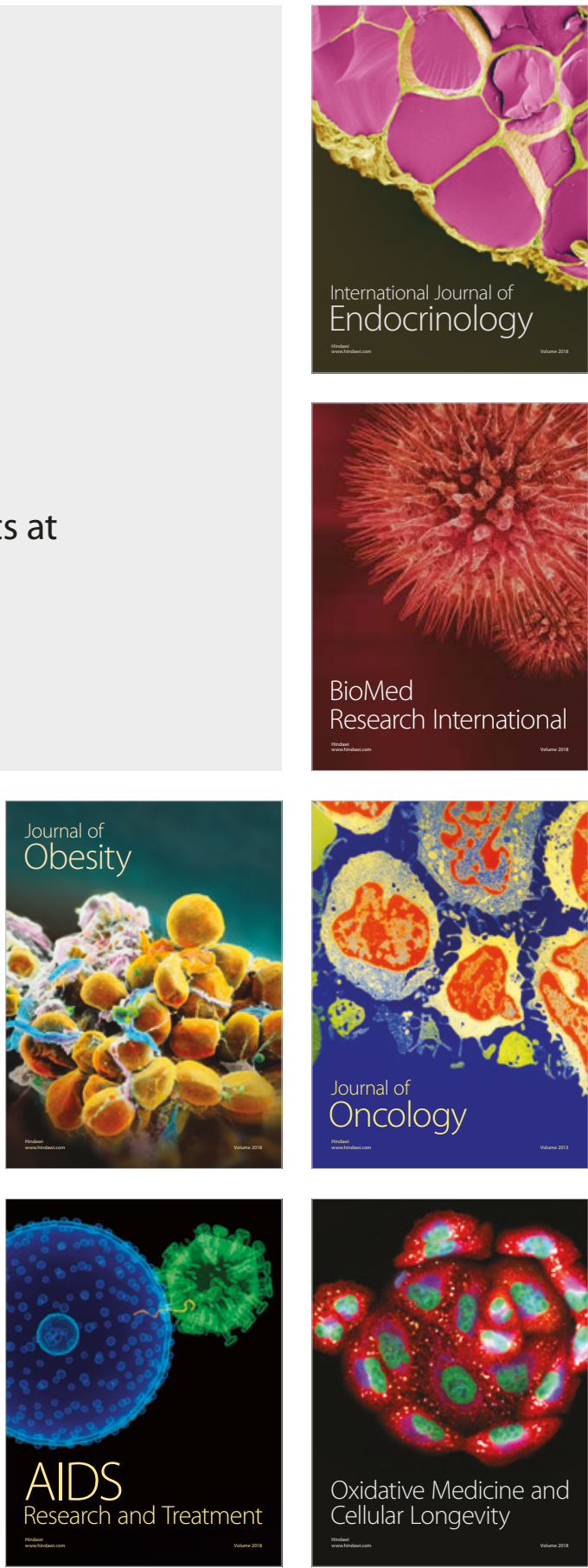